\title{
Daily to Decadal Modulation of Jet Variability
}

\author{
Tim Woollings, ${ }^{\mathrm{a}}$ Elizabeth Barnes, ${ }^{\mathrm{b}}$ Brian Hoskins, ${ }^{\mathrm{c}, \mathrm{d}}$ Young-OH KwON, ${ }^{\mathrm{e}}$ Robert W. Lee, \\ CAmille Li, ${ }^{\mathrm{g}, \mathrm{h}}$ ERICA MAdOnNa, ${ }^{\mathrm{g}, \mathrm{h}}$ MARIE MCGraw, ${ }^{\mathrm{b}}$ Tess PARKer, ${ }^{\mathrm{a}}$ ReginA Rodrigues, ${ }^{\mathrm{i}}$ \\ Clemens SPENSBERGER, ${ }^{\mathrm{g}, \mathrm{h}}$ AND KeITH Williams ${ }^{\mathrm{j}}$ \\ ${ }^{a}$ Department of Physics, University of Oxford, Oxford, United Kingdom \\ ${ }^{\mathrm{b}}$ Department of Atmospheric Science, Colorado State University, Fort Collins, Colorado \\ ${ }^{\mathrm{c}}$ University of Reading, Reading, United Kingdom \\ ${ }^{\mathrm{d}}$ Imperial College, London, United Kingdom \\ ${ }^{\mathrm{e}}$ Woods Hole Oceanographic Institution, Woods Hole, Massachusetts \\ ${ }^{\mathrm{f}}$ National Centre for Atmospheric Science, Department of Meteorology, University of Reading, Reading, United Kingdom \\ ${ }^{\mathrm{g}}$ Geophysical Institute, University of Bergen, Bergen, Norway \\ ${ }^{\mathrm{h}}$ Bjerknes Centre for Climate Research, Bergen, Norway \\ ${ }^{i}$ Department of Geosciences, Federal University of Santa Catarina, Santa Catarina, Brazil \\ ${ }^{\mathrm{j}}$ Met Office, Exeter, United Kingdom
}

(Manuscript received 2 May 2017, in final form 20 October 2017)

\begin{abstract}
The variance of a jet's position in latitude is found to be related to its average speed: when a jet becomes stronger, its variability in latitude decreases. This relationship is shown to hold for observed midlatitude jets around the world and also across a hierarchy of numerical models. North Atlantic jet variability is shown to be modulated on decadal time scales, with decades of a strong, steady jet being interspersed with decades of a weak, variable jet. These modulations are also related to variations in the basinwide occurrence of highimpact blocking events. A picture emerges of complex multidecadal jet variability in which recent decades do not appear unusual. An underlying barotropic mechanism is proposed to explain this behavior, related to the change in refractive properties of a jet as it strengthens, and the subsequent effect on the distribution of Rossby wave breaking.
\end{abstract}

\section{Introduction}

Shifts of the jet streams are the dominant source of variability in weather patterns across much of the midlatitudes (e.g., Hurrell and Deser 2009). Jet shifts are associated with altered storm-track paths and with changes in the regions that experience a mild oceanic influence. Several recent seasons of extreme weather were driven by jet shifts as a proximate cause. In the 2009/10 winter, for example, severe cold over both North America and Eurasia was caused by an extreme southward displacement of the North Atlantic jet, which persisted for most of the winter (Seager et al. 2010). Just two years later the 2011/12 winter was dominated by an almost unprecedented northward shift of the jet, leading to opposite impacts in many regions (Santos et al. 2013).

Corresponding author: Tim Woollings, tim.woollings@physics. ox.ac.uk
Such events have led some to ask whether the variability of midlatitude flow has been increasing (e.g., Hanna et al. 2015). A particular focus has been on the recent period of dramatic sea ice loss, which has been suggested to have weakened the jets and hence made them more susceptible to amplified and persistent wave anomalies (Francis and Vavrus 2012). While this hypothesis has not been widely supported by observational (Barnes 2013), theoretical (Hoskins and Woollings 2015), or modeling studies (Hassanzadeh et al. 2014; Cattiaux et al. 2016; Sellevold et al. 2016), it has raised interesting questions over how midlatitude variability is expected to alter in response to a change in the mean state.

In this paper we focus not on the wavelike variability along the jets, but instead on the meridional shifting of jets on a regional, ocean-basin scale. These shifts are the physical phenomena underlying many regional teleconnection patterns such as the North Atlantic Oscillation (Athanasiadis et al. 2010). We identify a clear link 


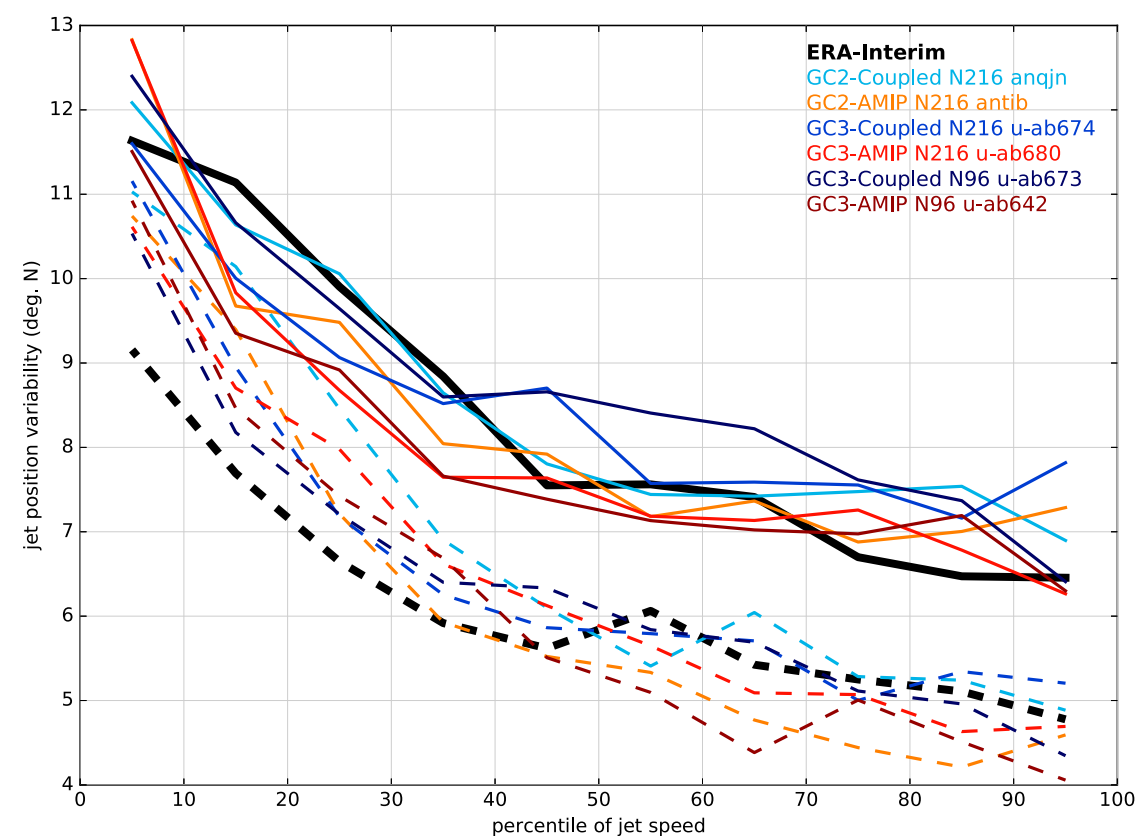

FIG. 1. Observed and modeled eddy-driven jet analysis using the method of Woollings et al. (2010) applied to 850-hPa zonal wind over the North Atlantic. Each line shows the standard deviation of daily jet latitude when the data are binned according to the jet speed (percentiles, with a bin width of $10 \%$ ). Solid lines are for winter, dashed lines for summer. Observational results are from ERA-Interim over the period 1979-2015. The model simulations (19812008) are from different global coupled versions (GC2 or GC3) and resolutions (N96 and N216) and are either coupled or atmosphere only (AMIP).

between the speed of a jet and the magnitude of its shifting variability. This link is apparent in a hierarchy of numerical models as well as in observed jets from around the world and across the seasons.

We then focus on the North Atlantic where distinct multidecadal variations of the speed of the jet have been identified (Woollings et al. 2015). Here we show that these variations were indeed accompanied by changes in the magnitude of shifting variability. We also examine the link with blocking, a synoptic pattern that is often linked with high-impact weather on the weekly time scale (e.g., Buehler et al. 2011). Blocking over the North Atlantic is strongly linked to jet variability. For example, the recent unusual jet winters also exhibited strong but distinct blocking anomalies, with the 2009/10 jet being shifted south of blocking over Greenland and the 2011/12 jet shifted north of blocking over southwest Europe (Santos et al. 2013). Hence, we show that decadal increases in jet position variability are linked to increased blocking over both Greenland and parts of Europe. These basinwide variations in blocking have been implicated in contributing to multidecadal ocean variability (Häkkinen et al. 2011).

Finally, based on the observational and modeling evidence we suggest a theoretical mechanism to explain the link between the speed of a jet and its variability in position.

\section{Observed and simulated midlatitude jet behavior}

We begin with analysis of the North Atlantic jet using the approach of Woollings et al. (2010). This entails using the low-level $(850 \mathrm{hPa})$ zonal wind to identify the location of the eddy-driven jet as distinct from the subtropical jet, which is solely an upper-tropospheric feature. The daily mean wind is averaged over the sector $0^{\circ}-60^{\circ} \mathrm{W}$ and 10 -day low-pass filtered before the latitude of maximum wind is identified [see Woollings et al. (2010) for more details]. The thick black lines in Fig. 1 have been derived by applying this method to ERA-Interim (Dee et al. 2011), in both winter and summer. The daily jet latitude has been binned according to the speed of the jet, and the lines show the standard deviation of the jet latitude in each bin. Hence, in both seasons the weaker jet speeds are associated with larger variability in the jet latitude.

This relationship is not a trivial consequence of averaging. If the jet shifts strongly during a given period then the average over the period will be a broad, weak 

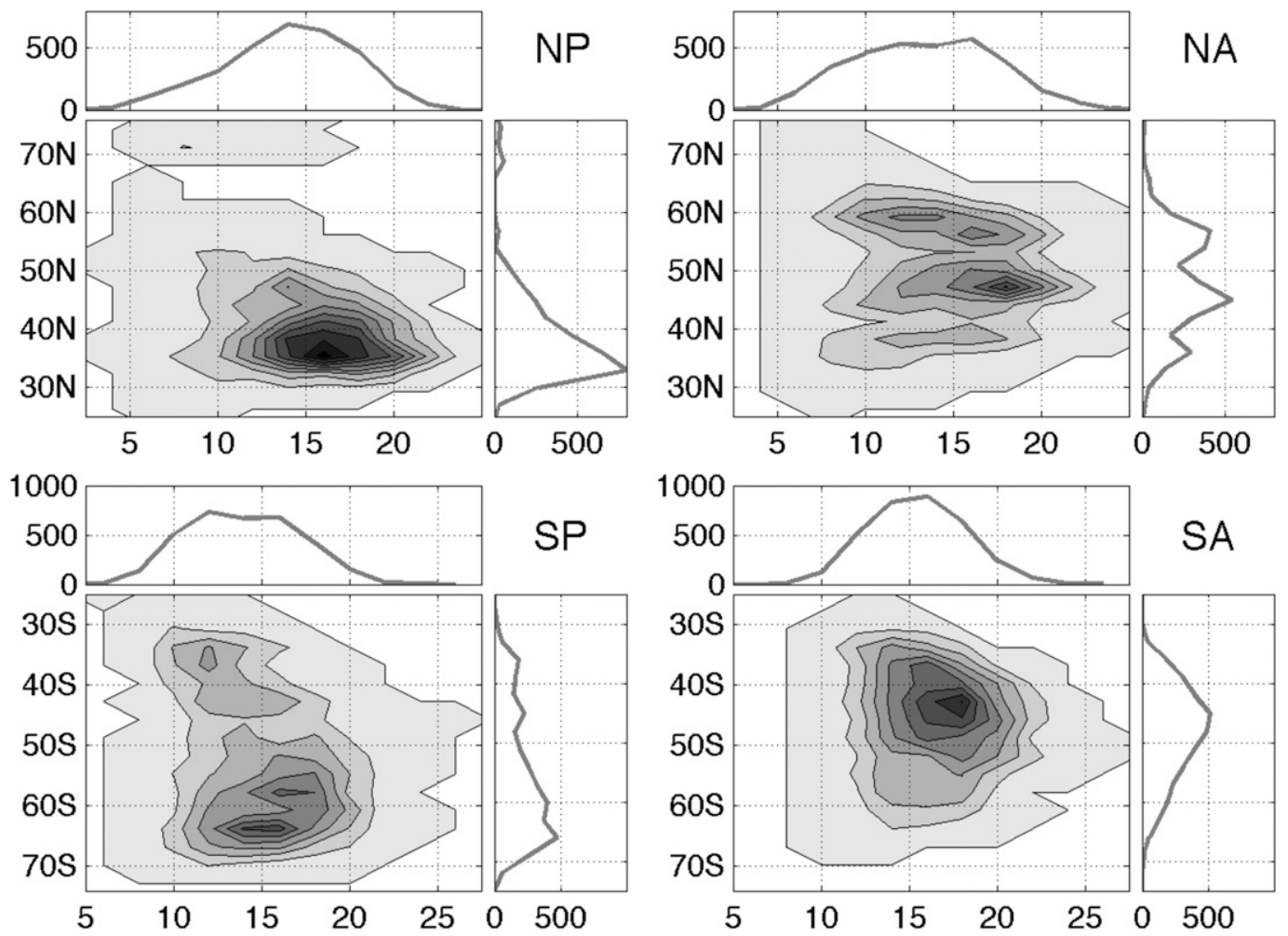

FIG. 2. Wintertime distributions of the Woollings et al. (2010) jet diagnostics in the North Pacific (NP; $150^{\circ} \mathrm{E}-$ $\left.150^{\circ} \mathrm{W}\right)$, North Atlantic (NA; $\left.0^{\circ}-60^{\circ} \mathrm{W}\right)$, South Pacific $\left(\mathrm{SP} ; 70^{\circ}-170^{\circ} \mathrm{W}\right)$, and South Atlantic $\left(\mathrm{SA} ; 50^{\circ} \mathrm{W}-10^{\circ} \mathrm{E}\right)$. Twodimensional distributions show the jet speed on the $x$ axis $\left(\mathrm{m} \mathrm{s}^{-1}\right)$ and jet latitude on the $y$ axis, with the data binned every $2 \mathrm{~m} \mathrm{~s}^{-1}$ and $3^{\circ}$ of latitude. Contours are drawn at intervals of 20 occurrences. Corresponding one-dimensional distributions are shown alongside each plot. The data are from ERA-Interim (1979-2014) using 850-hPa zonal wind, with DJF and JJA seasons used as northern and southern winters, respectively.

jet, which is consistent with the relationship shown. However, both our jet latitude and speed diagnostics are derived by following the maximum wind in daily data, so our results do not simply reflect averaging in this way.

The colored lines in Fig. 1 present the same analysis applied to several different recent versions of the Met Office climate model (e.g., Williams et al. 2015). The dependence of jet latitude variability on jet speed is very robust, occurring clearly in each model version, at each resolution, and regardless of whether the atmospheric model is coupled to an ocean or not. The overall structure of behavior is well simulated by the model. It appears to slightly underestimate this dependence in winter and overestimate it in summer, although internal variability may not be adequately accounted for here, at least in the winter when the observed curves are less clearly distinct from the model ensemble.

As a summary of observed wintertime jet behavior in other regions we show two-dimensional distributions of the daily jet latitude and speed diagnostics in Fig. 2 . Similar plots, albeit based on considerably less data, were shown by Cressman (1950). The regions were chosen as representative of different jet configurations observed, including the split and single jets in the South Pacific and Atlantic sectors, respectively. In this index the North Atlantic jet exhibits a trimodal structure in jet latitude, with the strongest wind speeds occurring when the jet is in its central position, in agreement with Woollings et al. (2010). The jet speed is weaker on average when the jet is displaced to its northern or southern position. The two-dimensional distribution for the South Atlantic jet shows a triangular shape, which will be seen to occur in other cases as well. This indicates a relationship consistent with Fig. 1: while weak jets can occur over a wide range of latitudes, strong jets preferentially occur in the center of the latitude range, near the climatological jet position. This behavior is only somewhat evident in the South Pacific, where the distribution is complicated by the split jet structure that occurs over the New Zealand sector (Inatsu and Hoskins 2006). The North Pacific, however, is the case that least fits the general pattern, in that the strongest jets occur at the southern end of the latitude range. This likely reflects the pinning of the eddy-driven jet to the strong 

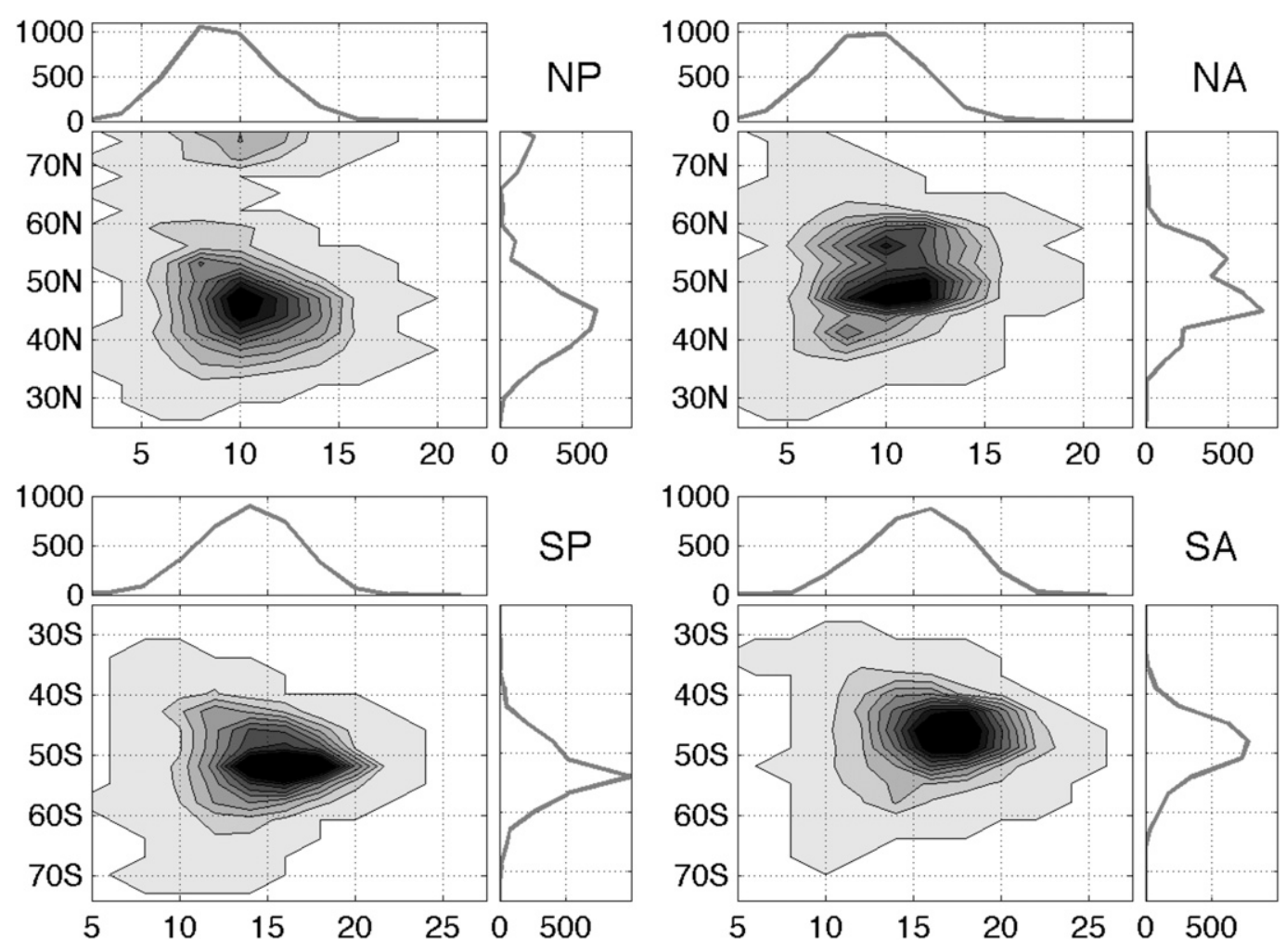

FIG. 3. As in Fig. 2, but for the local summer seasons.

subtropical jet in this region (e.g., Nakamura and Sampe 2002; Eichelberger and Hartmann 2007).

Corresponding distributions for the local summer seasons are shown in Fig. 3. These generally do show a somewhat triangular-shaped distribution, as in the South Atlantic winter case, indicating that the stronger jets occupy only the middle of the range of jet latitudes. Hence, observed jets in many regions show a reduced range of latitudinal positions when they strengthen. The exceptions to this behavior are related to specific winter cases involving interaction with a local subtropical jet.

By comparing Figs. 2 and 3 it is clear that summertime jets exhibit a smaller range of latitudes than wintertime jets, even though they are weaker. This contrast is likely a result of several different factors, such as the jets being located farther poleward, the baroclinic eddy driving being weaker, and the wave-breaking length scales being shorter (Feldstein 2007; Barnes and Polvani 2013; Woollings et al. 2014).

The jet identification method of Woollings et al. (2010) is relatively simplistic, using sector-averaged lowlevel flow that could be affected by orography. It also features a strong constraint that each day is uniquely identified with one jet maximum. Next we apply the method of Spensberger et al. (2017) to provide an alternative approach to the identification of jets. This method identifies local jet events as a function of both latitude and longitude based on a sign change of the wind shear on the 2-PVU surface ( $1 \mathrm{PVU}=10^{-6} \mathrm{~K} \mathrm{~kg}^{-1}$ $\mathrm{m}^{2} \mathrm{~s}^{-1}$ ), so that upper-level jets of a subtropical origin are identified as well as those that are eddy-driven or mixed. The method is applied directly to instantaneous 6-hourly data. The results are shown in Fig. 4, where the frequency of jet events is shown conditioned on their strength. This metric shows very similar behavior to that seen in Figs. 2 and 3: Weaker jets are seen to occur over a wide range of latitudes, but as the speed is increased the distributions contract around the climatological jet axes. This shows that the results shown so far are not artifacts of the zonally averaged or uniqueness properties of the Woollings et al. (2010) method. As another test, the basic result for the North Atlantic has been successfully reproduced using an approach following Archer and Caldeira (2008), which is thought to be less sensitive to noise in the zonal wind profile (using a mass-weighted integral of the zonal wind to define the jet center; not shown).

One particularly interesting aspect of Fig. 4 is that the subtropical jet over Asia exhibits similar behavior to the jets over the ocean basins. In this case the strongest jets occur just to the north of the climatological jet axis, which is shown by the blue lines. Weaker jets, however, are found either side of this region, covering a much 

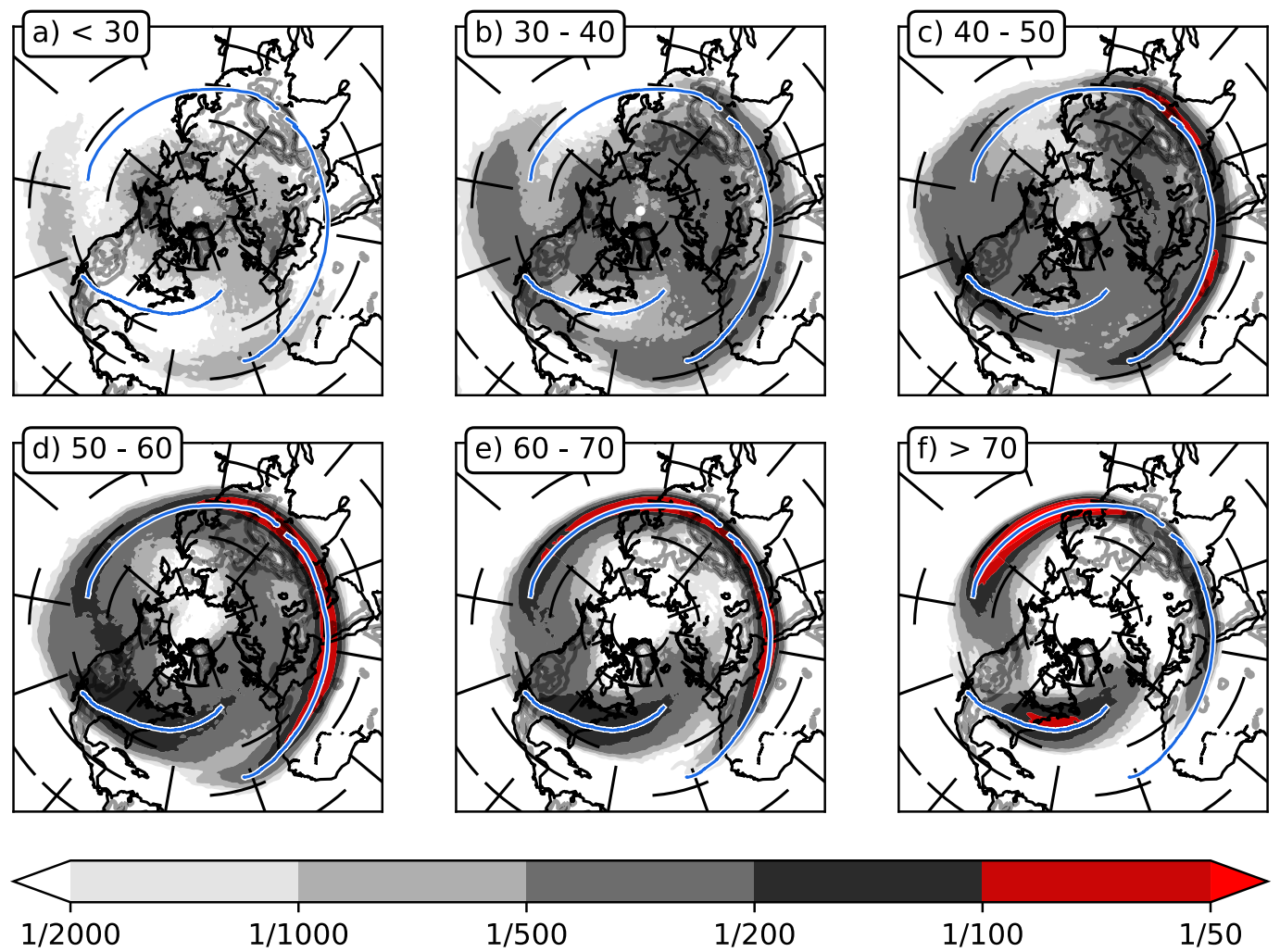

FIG. 4. Observational jet analysis using the method of Spensberger et al. (2017) applied to the 2-PVU surface in ERA-Interim in winter (1979-2014). Each panel shows the frequency of identified jets partitioned according to the speed of the jet $\left(\mathrm{m} \mathrm{s}^{-1}\right)$. Blue lines indicate the positions of the climatological jet axes.

wider range of latitudes. This provides some evidence that the inverse relationship between jet speed and the variability of jet latitude is a general property of atmospheric jets and, in particular, that it is not dependent on the presence of local baroclinic growth or diabatic effects (e.g., Li and Wettstein 2012; Papritz and Spengler 2015). While baroclinic eddies are often important in the storm-track regions, the fundamental mechanism for this relationship is more likely related to barotropic effects such as wave refraction or breaking, which can occur in purely subtropical as well as eddy-driven jets.

\section{Jet behavior in idealized models}

The previous section identified an inverse relationship between the speed of a jet and its variability in latitude. Given that this relationship is seen in many different regions and is well reproduced in a climate model, we now investigate whether it is also seen in simpler models. Idealized models often help to isolate the key physical processes and dependencies in a problem and put realistic features in a broader context (Held 2005).

We begin with a dry dynamical core model of the type that has been used to investigate many aspects of the large-scale atmospheric circulation. Specifically, we use simulations of the GFDL spectral dynamical core model performed by McGraw and Barnes (2016). The model was run at T42 horizontal resolution with 20 horizontal levels and zonally symmetric boundary conditions with no orography. Forcing was adapted from Held and Suarez (1994) to generate fixed forcing patterns representative of different seasons. The jet variability is characterized by identifying the maximum of the zonalmean zonal wind on the $775-\mathrm{hPa}$ surface and then fitting a second-order polynomial through the maximum, as in McGraw and Barnes (2016).

The lower panel of Fig. 5 shows the dependence of jet latitude variability on jet speed, in a similar format to Fig. 1. As before, there is a clear decrease in jet latitude variability when the jet is stronger, and this is seen for each of the four seasonal integrations. The standard deviation of latitude decreases from approximately $5^{\circ}$ to approximately $3^{\circ}$ of latitude as the jet speed increases. These magnitudes are weaker than the regional case in Fig. 1, as might be expected for zonal mean flow. Despite this, a very similar structure is apparent: the jet latitude variability decreases monotonically with increasing jet speed, but at a smaller rate for stronger jets. These 

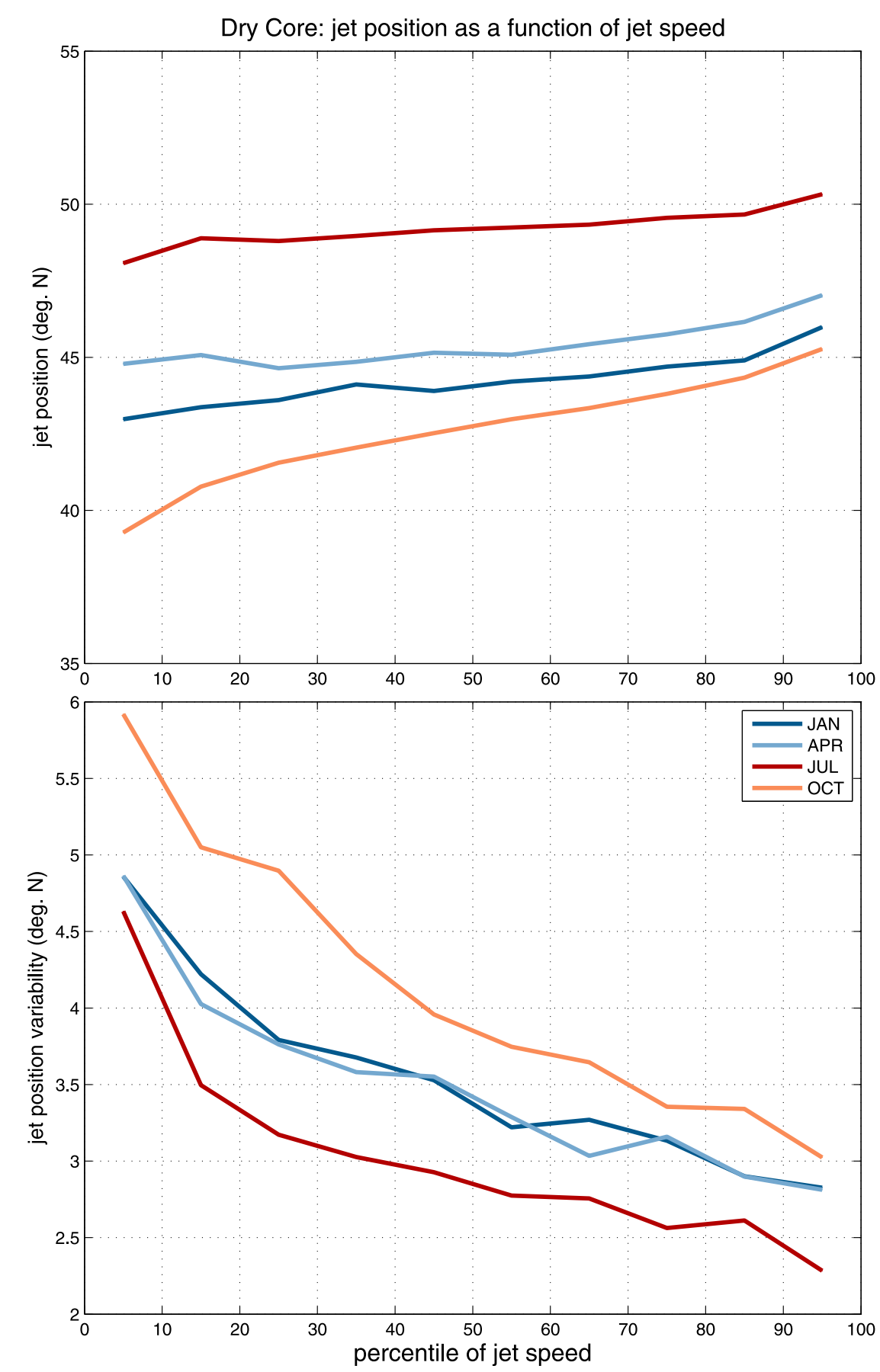

FIG. 5. Jet latitude diagnostics from the perpetual season dry dynamical core simulations of McGraw and Barnes (2016), binned according to the jet speed. (top) Mean jet latitude of each set. (bottom) Standard deviation of the jet latitude.

results show that this relationship is not restricted to regional jets, but is also evident in the zonal mean flow in a zonally symmetric setting.

One factor that should be considered is whether the mean position of the jet changes as its speed increases. Such a mean change in latitude might be expected to influence the variability in latitude (Barnes and Polvani 2013; Garfinkel et al. 2013) and hence could indicate an underlying mechanism. However, this does not appear to be the case. The upper panel of Fig. 5 shows how the mean jet latitude varies across the jet speed distribution. This does reveal a poleward drift of the jet as it 


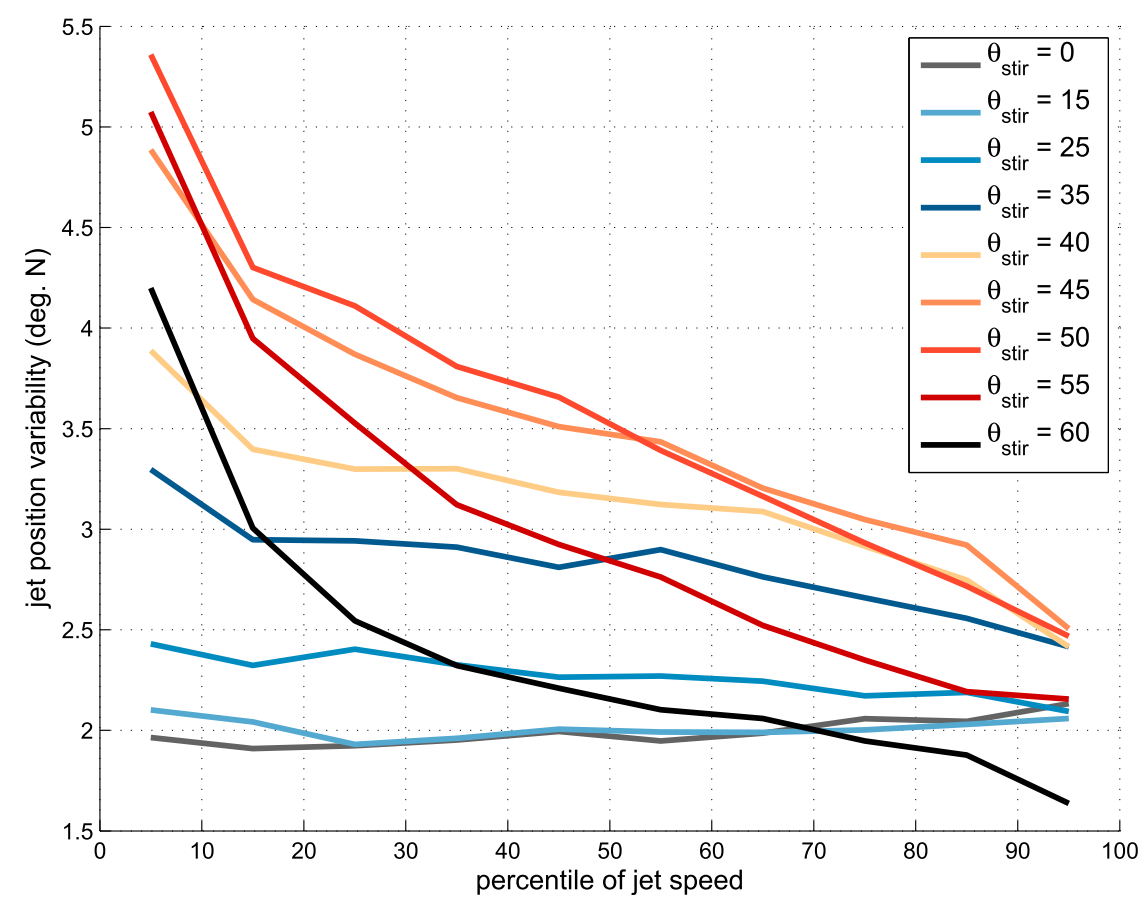

FIG. 6. Standard deviation of jet latitude, binned according to the jet speed, for the barotropic model experiments. Each line represents a different experiment in which the jet is forced at a different latitude, as given in the key.

strengthens, but this drift is generally weak (the October state stands out as being particularly sensitive in this regard). As we progress through the percentiles of jet speed there are instances when the jet latitude variability clearly decreases while the mean latitude is unchanged. This is in agreement with the observed results in Figs. 2-4, where the means of the jet latitude distributions are not seen to vary strongly with jet speed.

Next we consider an even simpler model, a nonlinear barotropic vorticity equation model on the sphere, forced by stochastic stirring in all zonal wavenumbers $\geq$ 4 to represent the effect of storm-track eddies. Rossby waves are generated and propagate away from the stirring region, accelerating a jet at the stirring latitude (Vallis et al. 2004). The jet can be imposed at any latitude by simply varying the latitude of the stirring, as in Barnes et al. (2010). This model has proved useful in disentangling the different dynamical feedbacks that influence jet variability (e.g., Barnes and Thompson 2014).

Figure 6 shows the dependence of jet latitude variability on jet speed for a range of simulations with different central stirring latitudes. For simulations in which the jet is located in the midlatitudes (i.e., poleward of about $30^{\circ} \mathrm{N}$ ), the jet latitude variability decreases with jet speed in a very similar manner to the previous results. Even the magnitude of this dependency is very similar to that in the dry dynamical core model of Fig. 5. Since the barotropic model contains a very limited set of physical processes, this result has immediate consequences: there is a basic underlying mechanism for this behavior that is not dependent on the details of the baroclinic flow or the storm tracks. In this model the statistics of the stirring do not change as the jet varies, so the result does not arise from any feedback between the stirring and the jet. However, the feedbacks between the jet and the eddies that result from stirring are fundamental to the variability, as will be discussed in section 5 .

Focusing now on the low-latitude jet cases (i.e., those equatorward of about $30^{\circ}$ in Fig. 6), we observe a striking contrast to the midlatitude results. For each of the jets located in the deep tropics, the jet latitude variability is entirely insensitive to the jet speed. Hence, we have identified an essential ingredient for our relationship to emerge: we require only a barotropic jet driven by statistically stationary stirring, so long as the jet is located in a domain of extratropical spherical geometry.

There are two clear consequences of this. The first is that we can rule out other seemingly trivial potential mechanisms. For example, it is possible that a weak jet is identified at a broader range of latitudes simply because the wind profile is flatter, and hence the jet latitude identified is more sensitive to noise in the data. An additional possibility is that the presence of a climatological 


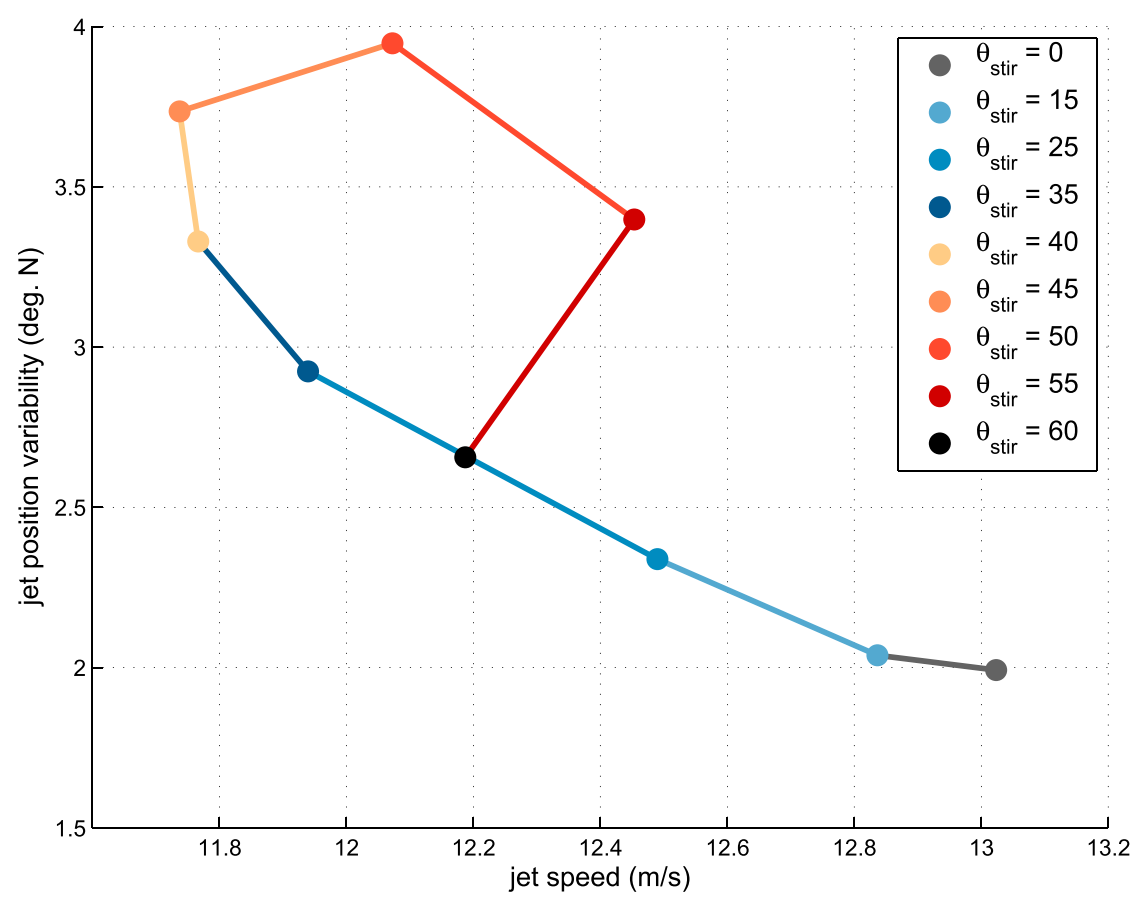

FIG. 7. Jet position variability (as a standard deviation) as a function of jet speed, taken across the barotropic model runs at different latitudes.

mean jet at a particular latitude might bias the detection algorithms such that stronger jets are found at that latitude. It is possible that one or another of these effects plays a role in our statistics in some of the cases we examine. However, if either of these was the underlying reason for the relationship between jet speed and variability in latitude, then it should operate on tropical jets as well as those in the extratropics. The balance of evidence from the different methods and models, and from the dynamical analysis of the observed flow below, suggests that the relationship arises from a dynamical mechanism rather than as an artifact of the analyses. The second consequence of the dependence on extratropical spherical geometry in this model is that it is very likely that this dynamical mechanism relies somehow on the characteristics of Rossby wave propagation and breaking. This will be pursued further in section 5 .

Before moving on, we briefly address one detail of the barotropic model experiments. Closer inspection of Fig. 6 reveals a nonmonotonic dependence on the stirring latitude. That is, the curves shift steadily up the chart as the stirring moves poleward to $50^{\circ}$, but then the curves move back down again. The reason for this behavior is explained, at least in part, by the changes in the mean jet speed as the jet moves poleward. This can be seen in Fig. 7, which shows the jet latitude variability for each simulation plotted against the mean jet speed. This shows that the average jet speed decreases as the stirring moves poleward to $45^{\circ}$, but beyond this the speed increases in the $50^{\circ}$ and $55^{\circ}$ runs before decreasing again at $60^{\circ}$. Figure 7 also highlights the inverse relationship between jet speed and jet latitude across the simulations; that is, simulations with a stronger mean jet tend to have weaker variability in jet latitude. However, Barnes and Hartmann (2011) argued that this was due to changes in the jet latitude, and thus spherical geometry, rather than a direct relationship between jet speed and variability. In section 5 we propose a mechanism involving wave propagation and breaking that may account for both of these phenomena.

\section{North Atlantic decadal variability}

In this section we focus on the North Atlantic where there is a great deal of literature on decadal atmospheric variability (e.g., Pinto and Raible 2012). Much of this decadal variability is associated with variations in the speed, rather than the latitude, of the eddy-driven jet (Woollings et al. 2015), which makes this region a natural place to focus on here. It has the additional benefit of a relatively good observational coverage over the twentieth century. In this paper we present diagnostics of jet variability and also blocking activity over the last century from both of the existing long reanalysis datasets. Most of the results are derived from the NOAA Twentieth Century Reanalysis (20CR; Compo et al. 

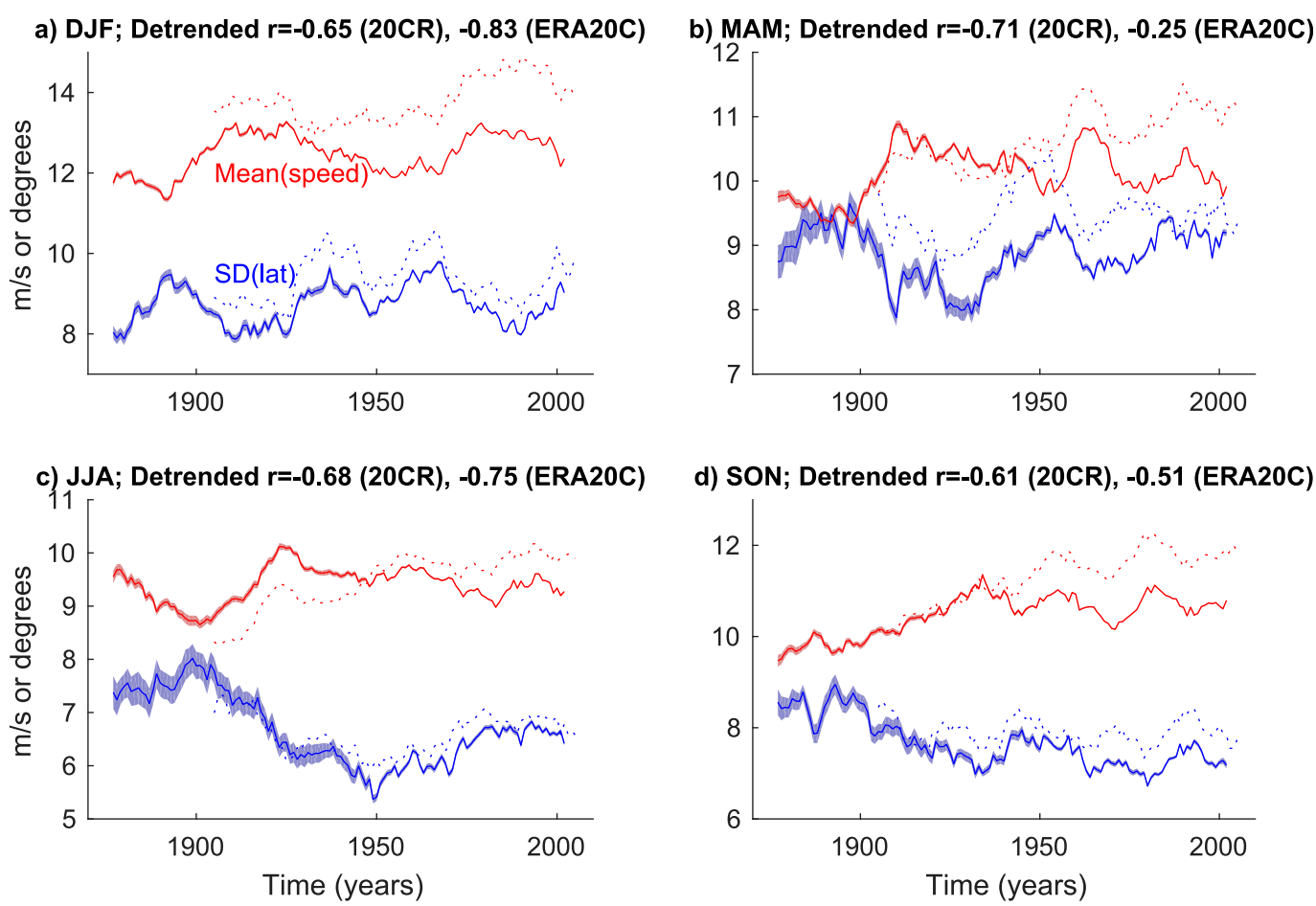

FIG. 8. Time series of the 11-yr mean jet speed (red) and running standard deviation of jet latitude (blue) of the North Atlantic eddy-driven jet. Solid lines are for NOAA 20CR and dotted lines for ERA20C. Shading for 20CR indicates the \pm 1 standard deviation uncertainty range across the ensemble. The time series are shown without detrending, but correlation values were calculated after linearly detrending the time series.

2011). The reanalysis was generated by assimilating surface pressure data only. To estimate the uncertainty, an ensemble approach was taken, and here we apply our analyses to each individual member, only averaging across the ensemble at the final stage. Woollings et al. (2014) used 20CR to analyze eddy-driven jet variability, finding that the variability in the North Atlantic is indeed better constrained by observations than in other regions.

First, we use the daily indices of jet latitude and speed derived from 20CR by Woollings et al. (2014). To characterize decadal variability in the jet speed we take the mean of the jet speed over an 11-yr running window. The analysis is performed season by season and is shown as red lines in Fig. 8. The decadal variations in winter jet speed are as presented by Woollings et al. (2014), and these are the variations underlying decadal variability in the winter NAO (Woollings et al. 2015). Decadal variability is also clear in other seasons, and in all cases the spread across the ensemble is low. Some fraction of the decadal variability may emerge from internal atmospheric variability as so-called climate noise (e.g., Deser et al. 2017). There is also evidence that some of the decadal jet variability might be driven by external factors such as ocean circulation (Gastineau and Frankignoul 2012; Sutton and Dong 2012); this is not investigated further in this paper, but there is some discussion at the end of this section. Note that the summer and autumn series in particular exhibit longterm trends that may arise from inhomogeneities in the reanalysis data.

Based on the results of previous sections, we anticipate that these decadal variations in jet speed might be associated with variations in the variance of jet latitude. To test this we take the standard deviation of the jet latitude index within the 11-yr running window. The standard deviation is taken across the 11 seasons of daily values and so combines intraseasonal and interannual variability on all time scales shorter than 11 years. The resulting time series are shown as blue lines in Fig. 8. As for the jet speed, the spread across the ensemble is smaller than the decadal variability. In each season this running variability measure is clearly anticorrelated with the decadal mean speed of the jet, so that the jet latitude will be anomalously variable during a decade when the mean jet speed is weak. This is in agreement with the general relationship between jet speed and jet latitude variability identified in this paper. Correlation values after linear detrending of the time series are given in the figure for each season. Detrending the time series 

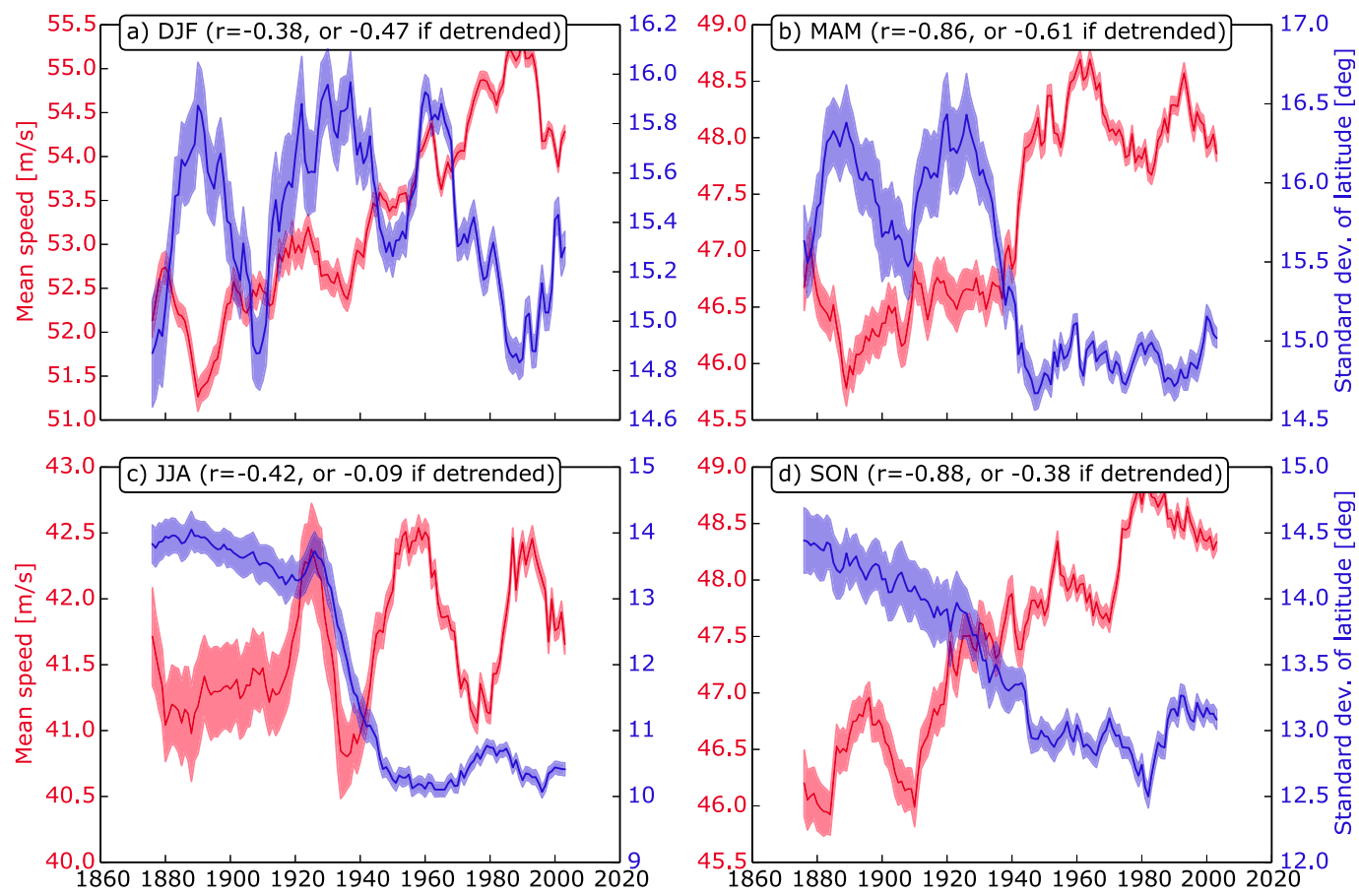

FIG. 9. As in Fig. 8, but based on the jet identification method of Spensberger et al. (2017). All points along all jet axes in the Atlantic sector $\left(20^{\circ}-90^{\circ} \mathrm{N}, 70^{\circ} \mathrm{W}-10^{\circ} \mathrm{E}\right)$ at the relevant times are combined into one array before calculating the mean and standard deviation.

removes the potentially artificial drift in some seasons and makes the correlation values more consistent across seasons (from $r \sim-0.6$ to -0.7 ). As before, correlations were performed for each ensemble member separately before taking the ensemble mean.

We also apply the same diagnostics to the ECMWF Twentieth Century Reanalysis (ERA20C) of Poli et al. (2016). This covers the period 1900-2010 and was generated in a similar manner to $20 \mathrm{CR}$, by assimilating only surface pressure and marine wind observations. The ERA20C results (dotted lines in Fig. 8) show some disagreement with $20 \mathrm{CR}$, for example, in the absolute values in some cases and also in some of the long-term trends. The general decadal variability is similar, however, and as before the jet speed and jet latitude variability are anticorrelated in each season. All correlations are stronger than -0.5 , with the one exception of the spring series from ERA20C. Hence, this second long reanalysis product supports the results obtained from 20CR.

As a further test of this result, we show in Fig. 9 a similar analysis of 20CR using the jet detection method of Spensberger et al. (2017), as used in Fig. 4. To recap, this method identifies localized jet events via tropopause level wind shear, hence avoiding errors associated with zonal averaging or tilted jets, for example. Owing to data restrictions, this analysis was performed on the $250-\mathrm{hPa}$ surface rather than 2 PVU. In addition to the identification algorithm, differences from Fig. 8 might be expected to arise from the use of upper-level data. This means that subtropical jets are included in this analysis, whereas they are excluded by the Woollings et al. (2010) method. In addition, the upper troposphere is expected to be less well constrained by the surface observations than the lower-tropospheric data used by Woollings et al. (2010). Indeed, the spread across the ensemble is slightly larger in Fig. 9 than Fig. 8, although this spread is still weaker than the decadal variability. Despite these expected differences, there are several common features between the two figures, particularly on the decadal scale. There are also larger centennial trends in Fig. 9 and a couple of suspicious discontinuities around the middle of the data period when the number of observations changes rapidly (Compo et al. 2011). The correlation values vary more strongly between the seasons, though as before these are made more consistent by detrending. The exception is the summer season, which shows an unrealistic step change in jet latitude variability and hence the detrended series are uncorrelated. Excluding summer the detrended correlation values are in the range from $r \sim-0.4$ to -0.6 . Overall, this analysis lends support to the existence of a link on the decadal time scale between the speed of the jet and its variability in latitude, despite the challenges associated with 
constraining upper-tropospheric gradients in the early decades of 20CR.

We now complement the jet analyses with diagnostics of atmospheric blocking in 20CR. Blocking is an often high-impact weather pattern in which the prevailing westerly winds and storm systems are blocked by a persistent, usually anticyclonic, anomaly (Rex 1950). Blocking often arises from the breaking of Rossby waves, which leads to a reversal of the normal equatorward gradient of geopotential height (Pelly and Hoskins 2003). Blocking is of interest not only for its association with high-impact weather, but also for its close link with jet variability on multiple time scales (Croci-Maspoli et al. 2007; Gollan et al. 2015). A particular motivation of the work here is the study of Häkkinen et al. (2011), who identified decadal variations in North Atlantic blocking that appeared related to variations in ocean circulation (see also Davini et al. 2015; Gray et al. 2016). Their mechanism relates to blocking activity integrated over a wide North Atlantic/ European region, which we anticipate is linked to variations in the amount of jet latitude variability. Following their study we focus on wintertime blocking, though we have also performed this analysis for summer. This gave somewhat similar results but with weaker correlations. We note that, in our diagnostic at least, there is very little summer blocking over the North Atlantic.

We use the Scherrer et al. (2006) approach to identify blocking based on a reversal of the geopotential height gradient at $500 \mathrm{hPa}$. Time and space scales are imposed to ensure the events are persistent, large-scale, and stationary. Hence, this index identifies high-impact synoptic events rather than necessarily jet variability in general. As in our other analyses, this method is applied separately to each individual ensemble member of 20CR. The resulting climatology of blocking over the North Atlantic is shown in Fig. 10c. This identifies two dominant centers of blocking occurrence, one over Greenland and the other over northwest Europe. This index is used because it is very convenient to apply to large datasets and will capture blocking events. However, it is recognized that it also captures other phenomena such as small fluctuations in the southwestnortheast-sloping subtropical Atlantic ridge.

Motivated by Häkkinen et al. (2011) we perform an EOF analysis of the winter-mean blocking frequency, and the first two EOF patterns are shown in Figs. 10a and $10 \mathrm{~b}$. The first EOF consists of a dipole in blocking occurrence between mid- and high latitudes. The associated time series is correlated with both the NAO and the mean jet latitude (not shown). This reflects wellknown associations in the literature: Greenland blocking is associated with a southward jet shift in a classical (a) EOF $1(19.7 \%)$

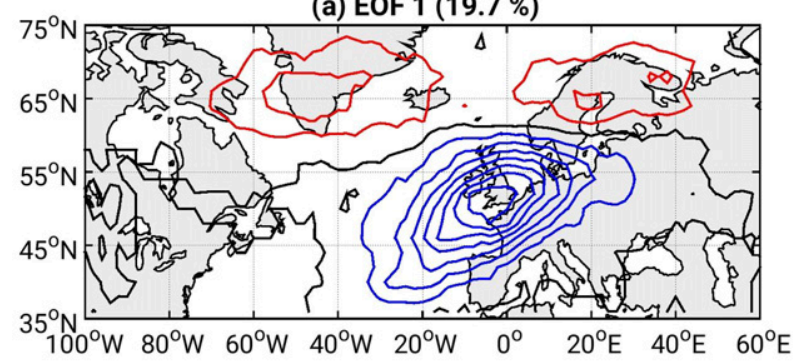

(b) EOF $2(10.9 \%)$

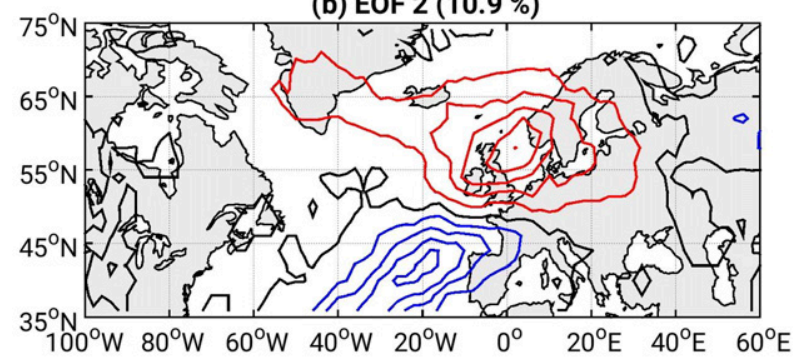

(c) Climatological Mean

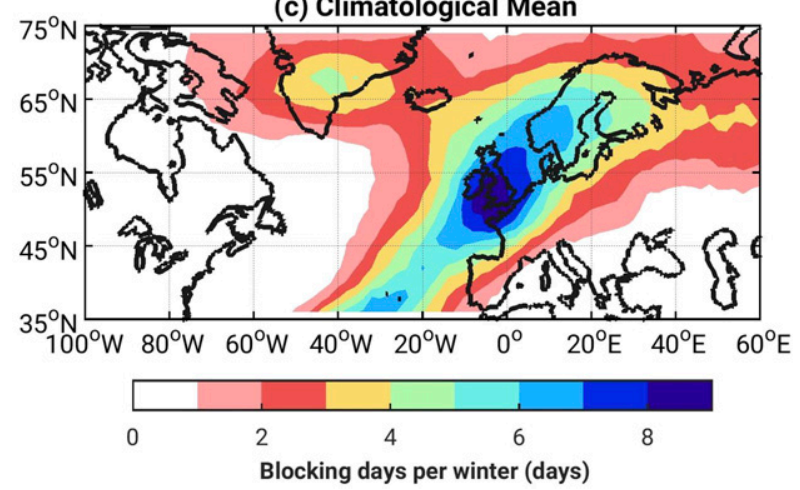

FIG. 10. (a),(b) Leading two EOF patterns of DJF-mean blocking frequency from 20CR over the period 1981-2010. (c) The climatological blocking frequency. The contour interval is 1 day per season. Linear trends were removed prior to calculating the EOFs.

NAO - pattern (Woollings et al. 2008), while blocking over western Europe is often associated with a northward shift of the jet (Davini et al. 2012).

Here, we focus on the second EOF, in which blocking over Greenland, Iceland, and northwestern Europe covaries. This is very similar to the blocking pattern that Häkkinen et al. (2011) identified as corresponding to the second EOF of wind stress curl. As in their paper, it correlates well with a simple average of blocking frequency over the northern North Atlantic (not shown). Figure 11 shows the principal component time series of EOF2 in blue. This is found to correlate well with the 11-yr running standard deviation of jet latitude from Fig. 8, which is shown in black. Hence, the decadal modulations of jet variability we identified are linked with variations in the occurrence of blocking averaged over the northern North 


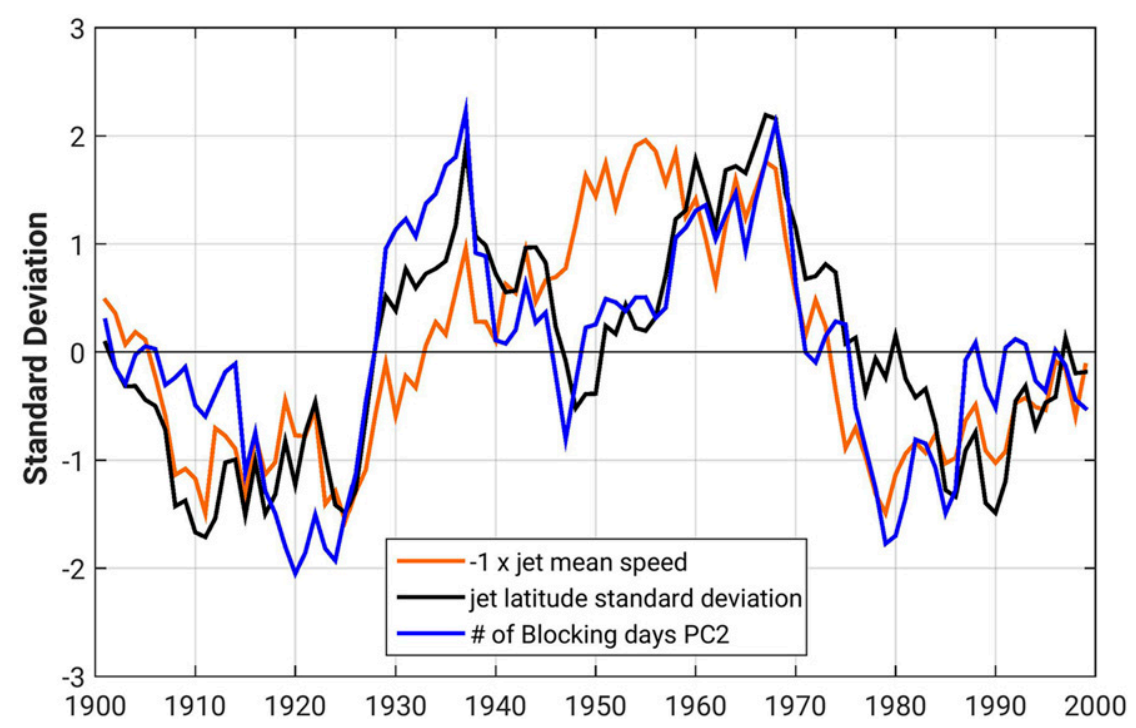

FIG. 11. Time series of North Atlantic winter blocking and jet diagnostics from 20CR. All series have been smoothed with an 11-yr running mean.

Atlantic. As described above, blocking over Greenland is commonly associated with a southward shifted jet, while blocking over Scandinavia and the British Isles is more often associated with a northward shifted jet. A decade exhibiting a positive EOF2 pattern will feature enhanced blocking over both of these regions, and hence enhanced occurrence of both southward and northward shifted jet events. This is consistent with an increase in jet variability, as is seen to coincide with the positive EOF2 of blocking. Figure 11 also shows the negative of the mean jet speed (in orange). As expected from earlier results, this indicates covariability with a weaker jet corresponding to enhanced basinwide blocking and strong variability in jet position. Correlations between blocking and the jet time series peak at lag zero with $r \sim 0.8$ (not shown), which is significant at the $95 \%$ level (there is a small variation of order 0.05 between ensemble members).

Häkkinen et al. (2011) associated a decadal-scale increase in blocking over both Greenland and Europe with a weakening of the climatological wind stress curl pattern. This appears to lead to weaker gyre circulations and increased northward transport of warm subtropical water to higher latitudes. Here we show that this situation is also associated with a weaker mean jet speed and an increase in the variability of jet latitude, a factor that has also been linked to increased exchange of water masses between the gyres (Czaja 2009).

\section{Barotropic mechanism}

In this section we propose a possible mechanism to explain the inverse relation between the strength of a jet and its variability in latitude. Since this relationship has been shown to hold for midlatitude jets in the barotropic model, we suggest that there is an underlying barotropic mechanism. Baroclinic eddy growth may, of course, play a role in modifying the behavior in more realistic cases, but we focus here on a mechanism that can explain the behavior across our model hierarchy.

We follow the approach of Barnes and Hartmann (2011), who diagnosed a negative feedback acting on the jet when it strengthens. In the barotropic model, when the jet is stronger the waves become more trapped in the jet, as in Hoskins and Ambrizzi (1993). Since the waves are less able to propagate out of the jet, there is a weakening of the momentum convergence into the jet, and this acts to weaken it. Hence, a negative feedback is realized, whereby the original anomaly in jet speed is weakened.

Motivated by these results, we propose a hypothesis to explain the changes in jet latitude variability. This variability is closely associated with the breaking of Rossby waves on either side of the jet. Wave breaking acts to decelerate the zonal wind locally (e.g., Edmon et al. 1980; Strong and Magnusdottir 2008), and hence breaking on the equatorward flank of the jet pushes it poleward, and vice versa. This mechanism has been diagnosed in barotropic (Barnes and Hartmann 2012) and baroclinic (Kunz et al. 2009) idealized models as well as in observations (Benedict et al. 2004; Rivière and Orlanski 2007). Strong variability in jet latitude therefore arises in a configuration where large-scale breaking occurs relatively often on both flanks of the jet, since there will be periods of poleward breaking and persistent equatorward jet shifts (e.g., Woollings et al. 2008) 
but also equatorward breaking and persistent poleward shifts (e.g., Davini et al. 2012). Our hypothesis is therefore that the variability in jet latitude is reduced when the wave breaking occurs predominantly on one side of the jet. The preference for the turning of waves (rather than breaking) on the poleward flank of midlatitude jets then naturally suggests this concentration of wave breaking will occur on the equatorward side. The proposed importance of the poleward turning latitude is also supported by the barotropic model results, as only the midlatitude jet cases exhibit a relevant poleward turning latitude, and it is these that show the relationship between jet speed and jet latitude variability.

For evidence in support of this hypothesis we return to the observed flow in the North Atlantic sector, because the decadal variability is a focus of this paper. Similar analysis for the barotropic model is presented in Barnes and Hartmann (2011). Using monthly data from ERAInterim, we compare diagnostics of Rossby wave refraction and breaking in strong and weak jet periods. These periods were defined by zonally averaging the $700-900-\mathrm{hPa}$ zonal wind over $0^{\circ}-60^{\circ} \mathrm{W}$ and compositing the $25 \%$ of months with the strongest and weakest winds. These sets match those of the strongest and weakest jets according to the Woollings et al. (2010) index (not shown). There is no significant difference in the mean jet latitude of the two sets, though the weak jet set has a considerably greater spread of jet latitudes (not shown), as expected from the results of section 2.

As shown by Hoskins and Karoly (1981), changes in the propagation of Rossby waves can be understood using the stationary wavenumber, defined as

$$
K^{*}=\cos \phi\left(\frac{\beta^{*}}{[u]-c}\right)^{1 / 2}
$$

Here $\phi$ is the latitude, $u$ is the westerly zonal wind speed, with [] denoting a sector zonal average, and $c$ is the wave phase speed. The term $\beta^{*}$ is the meridional gradient of absolute vorticity on the sphere, given by

$$
\beta^{*}=\frac{2 \Omega \cos \phi}{a}-\frac{1}{a^{2}} \frac{\partial}{\partial \phi}\left[\frac{1}{\cos \phi} \frac{\partial}{\partial \phi}(u \cos \phi)\right]
$$

where $\Omega$ and $a$ are the angular velocity and radius of Earth, respectively. The term $K^{*}$ acts like an index of refraction for Rossby waves, so that the wave paths are bent toward higher values of $K^{*}$.

Figure 12 shows the latitudinal profiles of the composite $300-\mathrm{hPa}$ zonal wind $\left(0^{\circ}-60^{\circ} \mathrm{W}\right)$ and the $K^{*}$ diagnostic calculated from it. Upper-level wind such as this is most appropriate for deriving $K^{*}$, though note that the wind at this level includes a contribution from

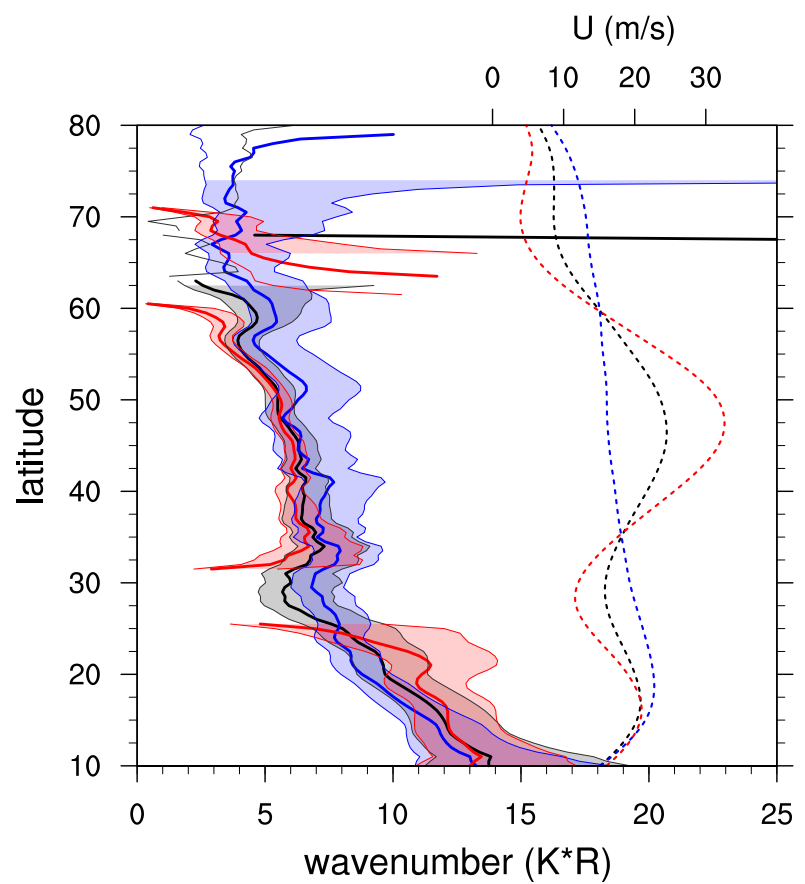

FIG. 12. Diagnostics of composite fields of the $25 \%$ strongest and weakest jet months in the North Atlantic in ERA-Interim (19792014). Dashed lines show the composite mean 300-hPa wind speed and solid lines show the stationary wavenumber $K^{*}$ multiplied by the radius of Earth so as to correspond to zonal wavenumbers. Colors are black for the climatology, blue for the weakest months, and red for the strongest months. The term $K^{*}$ was calculated assuming a phase speed of $9 \mathrm{~ms}^{-1}$, and the shading indicates the range when values of 6 and $12 \mathrm{~m} \mathrm{~s}^{-1}$ are used instead.

the subtropical jet, hence the lack of a distinct midlatitude wind maximum in the weak jet case. In calculating $K^{*}$ some choice of phase speed $c$ has to be made. Here, we choose a range of values of $c$ to indicate uncertainty in $K^{*}$, and it is only on the flanks of the jet that these uncertainty ranges do not overlap. In the strong wind case in particular, $K^{*}$ is undefined for some latitudes, when either $\beta^{*}$ or $[u]-c$ is negative, indicating linear wave propagation is not permitted according to the theory.

In the stronger wind case $K^{*}$ is decreased at most latitudes, particularly strongly on the flanks of the jet. These changes are qualitatively similar to those seen by Barnes and Hartmann (2011) in the barotropic model, suggesting that the same mechanism is acting in the observations as in the model. Decomposition of $K^{*}$ into its constituents (not shown) indicates that the change in $\beta^{*}$ is crucial for the decrease in $K^{*}$ on the jet flanks. This arises from the increased sharpness of the jet that affects the meridional relative vorticity gradient. The decrease in $K^{*}$ on the jet flanks means that only the longest waves are able to propagate out of the jet. 
a) weak wind composite

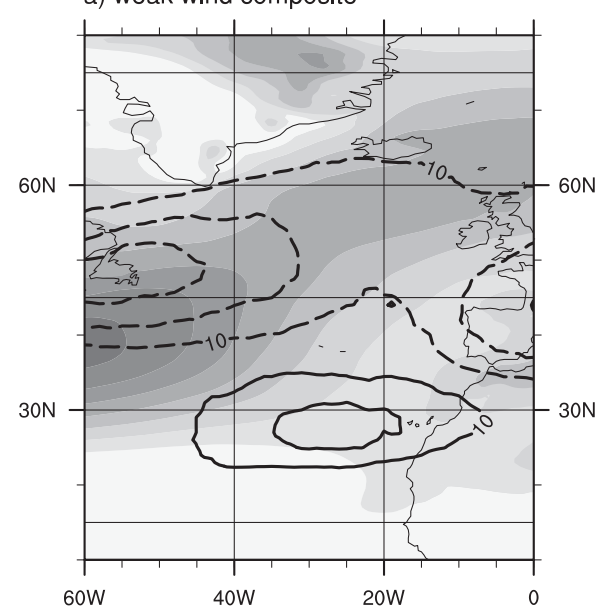

$60 \mathrm{~W}$ b) strong wind composite

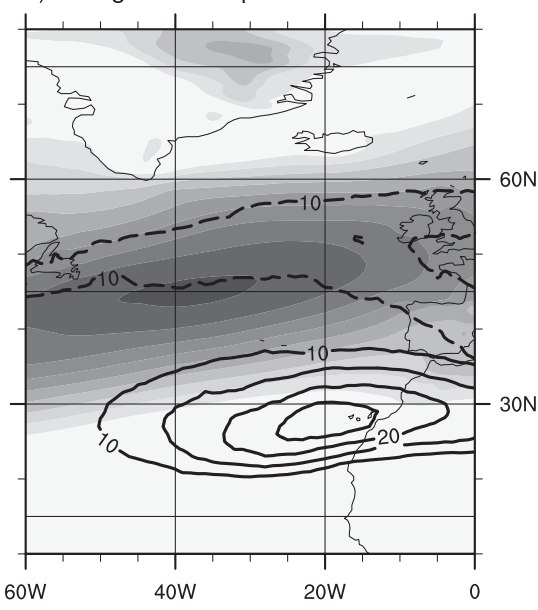

c) climatology DJF 1979-2014

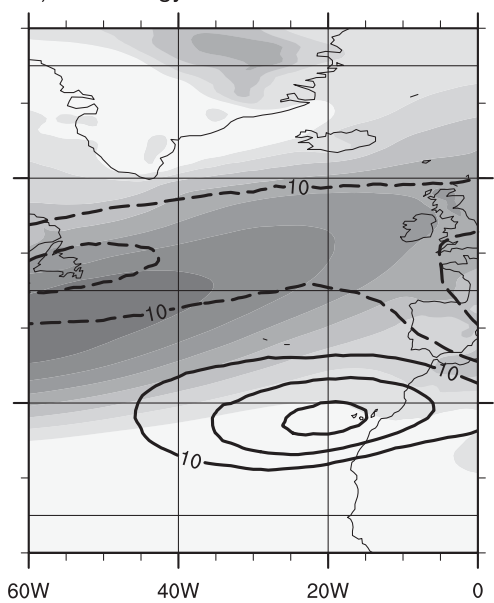

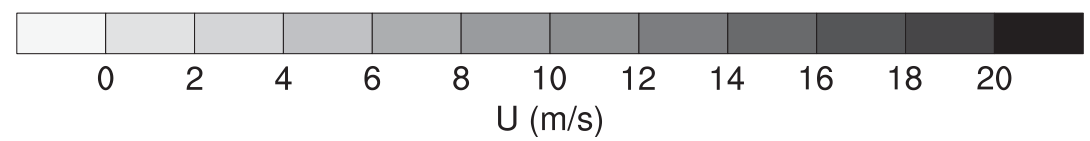

FIG. 13. Zonal wind (900-700 hPa) and Rossby wave-breaking frequency (\%) for the (a) weak and (b) strong wind composites and (c) the climatology. The wave breaking is given on isentropic surfaces of 320 (dashed) and $340 \mathrm{~K}$ (solid).

The poleward-moving waves are particularly strongly affected, since the trapping of waves is inherently easier on the poleward side of the jet due to the spherical geometry.

The associated changes in wave breaking are shown in Fig. 13. These diagnostics are derived from ERAInterim (Sprenger et al. 2017) using the method of Wernli and Sprenger (2007), which is based on the identification of potential vorticity streamers on isentropic surfaces. The wave breaking is shown at 320 and $340 \mathrm{~K}$. At $320 \mathrm{~K}$, most of the breaking will be cyclonic in nature and occur on the poleward side of the jet. In contrast, the breaking at $340 \mathrm{~K}$ will be largely anticyclonic and lie on the equatorward side of the jet (see Martius et al. 2007, their Fig. 5). The blocking diagnostics shown in section 4 are often related to wave breaking; however, the diagnostics in Fig. 13 are more general. All occurrences of wave breaking should be detected, without necessarily satisfying the rigorous time and space scales that we associate with blocking. Hence, transient events, which are often associated with significant momentum and vorticity fluxes, also contribute to these statistics.

As hypothesized, Fig. 13 shows systematic changes in the distribution of wave breaking as the jet strengthens. In the weak wind composite there is relatively frequent wave breaking on both sides of the jet. As hypothesized, however, these breaking events do not generally occur at the same time; simultaneous breaking on both sides of the jet was found to occur on less than $5 \%$ of the days in this set (not shown). Moving to the climatology, and then the strong wind composite, the frequency of poleward, cyclonic wave breaking is greatly reduced while the equatorward, anticyclonic breaking becomes more frequent. Very little cyclonic wave breaking remains in the strong wind composite, and what little there is occurs in a limited band of latitudes on the jet flank. Hence, the strong jet case, with weak variability in jet latitude, is indeed associated with a highly asymmetric distribution of wave breaking dominated by the equatorward region. Enhanced wave breaking on the equatorward side of the jet is consistent with enhanced convergence of eddy momentum flux into a stronger jet (e.g., Strong and Davis 2008; Woollings et al. 2015). Note that this is a different situation from some recent high-impact strong jet events where breaking occurred on both sides of the jet (e.g., Pinto et al. 2014). It is also distinct from the pattern of wave breaking that typically accompanies the NAO in this index, which was presented by Martius et al. (2007).

Schematics of our proposed mechanism are presented in Fig. 14, following those of Hoskins and Ambrizzi (1993). In the weak jet case, synoptic waves of wavenumber $k$ are generated within the jet and propagate both poleward and equatorward. The equatorwardmoving waves are able to propagate out of the jet and either break in the subtropics or are otherwise dissipated in the tropics. The poleward-moving waves eventually reach their turning latitude where $k=K^{*}$, at which point 

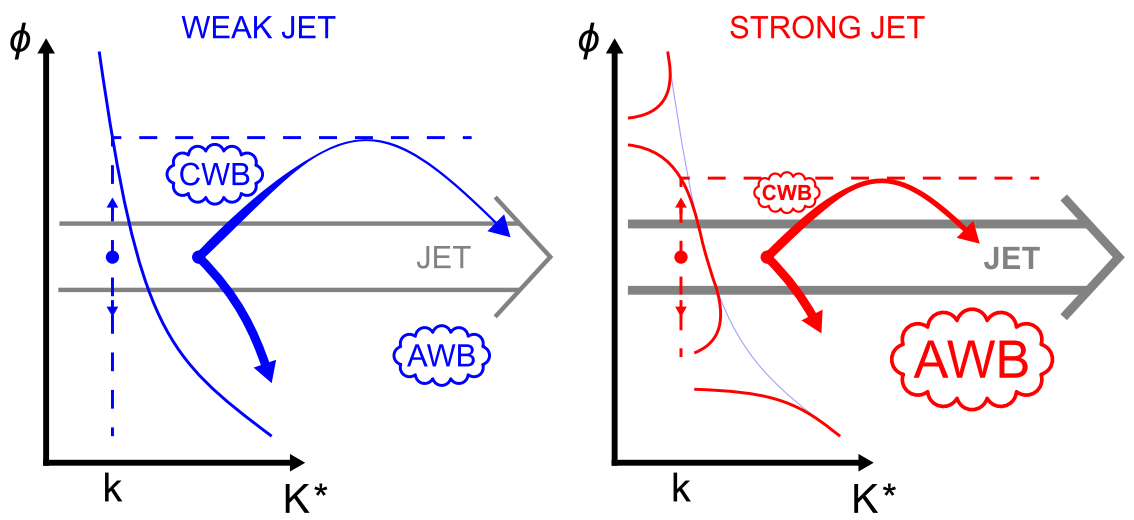

FIG. 14. Schematics of weak and strong jet states, showing $K^{*}$ as a thin line (as a function of latitude) and wave paths as thick lines (in the latitude-longitude plane). The evolution of a wave with wavenumber $k$ can be inferred by starting in the jet and following the dashed lines meridionally to the latitude where $k=K^{*}$. This sets the position of the turning latitude for wavenumber $k$. AWB and CWB stand for anticyclonic and cyclonic wave breaking, respectively. The thin blue line in the strong jet panel represents the $K^{*}$ profile in the weak jet case.

their wave vectors point due east and hence the waves are turned to propagate equatorward again. Not all poleward-moving waves reach the turning latitude, however. Owing to the weak relative vorticity gradient, this turning latitude is set largely by the planetary vorticity gradient, and hence there is a large region of weak westerly winds poleward of the jet maximum where waves can propagate. This region is favorable for cyclonic wave breaking, and hence the state supports relatively frequent wave breaking on both sides of the jet, leading to strong variability in jet latitude.

In the strong jet case, the poleward turning latitude has moved closer to the jet, as a result of the strong relative vorticity gradients on the jet flank. The region favorable for cyclonic wave breaking has been considerably reduced, such that very few waves break in this region. The vast majority are instead turned to propagate equatorward and add to the wave activity on the equatorward side of the jet. These waves generally break anticyclonically at the downstream end of the Atlantic jet. Applying the $K^{*}$ diagnostic to the downstream region only $\left(0^{\circ}-30^{\circ} \mathrm{W}\right.$; not shown $)$ indicates clear potential for breaking there, rather than the reflection suggested by the low $K^{*}$ values in the subtropics in Fig. 12, and the schematic reflects this. The strong jet state therefore lacks the variety in wave-breaking location that leads to a variable jet latitude. The preference for equatorward wave breaking in this state could also explain the small poleward shift of stronger jets in the dynamical core model (Fig. 5).

Comparing this picture with the observational results, a notable exception to this behavior is the North Pacific jet in winter. This jet is both strong and at the same time locked in an equatorward position with wave breaking largely on its poleward side. This exception can be understood as a consequence of the very strong subtropical driving of the jet in this case ( $\mathrm{Li}$ and Wettstein 2012), a factor that is not included in the mechanism proposed here.

\section{Discussion}

We have documented a general relationship: when a jet gets stronger, its variability in latitudinal position is reduced. This is observed in midlatitude jets around the world using two very different jet identification methods and is exhibited across the model hierarchy from stateof-the-art climate models down to a zonally symmetric barotropic model. Although not examined here, this relationship is also consistent with the transition to a stronger, more stable North Atlantic jet during the Last Glacial Maximum (Li and Battisti 2008; Rivière et al. 2010; Merz et al. 2015). An additional potential application of this work is to understanding climate model biases; our results suggest that a mean state bias in jet strength could impact the jet variability in the model.

We suggest an underlying barotropic mechanism for this behavior: a stronger jet gives enhanced refraction of Rossby waves, which are particularly well trapped on the poleward flank of the jet due to the spherical geometry and the change in the wind profile. A meridional asymmetry in the distribution of wave breaking develops, with most breaking occurring on the equatorward flank of the jet and very little on the poleward flank. Hence, the variety in wave-breaking location, a key source of jet variability, is greatly reduced. 
Several factors point toward such a mechanism: the relationship is seen in midlatitude jets in the barotropic model and is also observed in the subtropical jet over Asia where baroclinic storm-track processes are not active. It remains possible that baroclinic processes may play a role in some cases, perhaps by amplifying flow anomalies as in Barnes and Thompson (2014). It is also possible that some mechanism exists whereby a change in jet latitude variability affects the mean speed of the jet (i.e., in the opposite direction to our proposed mechanism). We have shown, however, that the results are not a consequence of temporal or spatial averaging that might be expected to give a trivial relationship of this nature.

Decadal variability in the North Atlantic also reflects this relationship, with decadal changes in jet speed modulating the amount of variability in latitude and also the basinwide occurrence of blocking. A novel aspect of this link is the importance of integrated blocking activity over a large region. This combines blocks of different types and different mean flow configurations, which contrasts with the use of fixed spatial patterns such as the NAO. Similarly, in terms of both the jet and the Rossby wave-breaking distributions, the decadal variability is manifested as changes in the amount of variety in flow configuration. These characteristics may help to explain the noted variability in the structure of teleconnection patterns on multidecadal time scales (Raible et al. 2006, 2014).

It is likely that atmosphere-ocean coupling plays a role in decadal variability in the North Atlantic sector (e.g., O'Reilly et al. 2016). For example, Woollings et al. (2015) found that decadal jet speed variability in a highresolution climate model was consistent with driving from subpolar gyre SST anomalies. Any ocean variability that strengthens the meridional temperature gradient across the storm track is likely to strengthen the jet (Brayshaw et al. 2011; Baker et al. 2017).

As discussed in the introduction, there is a rapidly growing body of literature suggesting that recent extreme events have occurred partly because of emerging anthropogenic effects such as amplified Arctic warming. Our results show that the variability of Atlantic jet position itself varies on decadal time scales. For example, the variability of wintertime jet latitude has increased over the last two decades, as the mean jet speed has weakened. However, this reflects the jet reverting to a more normal state after being unusually strong and steady around the 1980s and 1990s. In no season, according to our diagnostics, was the jet more variable in recent decades than in any earlier period. This highlights the importance of a long-time-scale perspective when analyzing recent events. It will be harder to attribute changes in variability over a short period to external driving if the level of jet variability is modulated on decadal time scales.

Acknowledgments. We would like to acknowledge funding from NERC and the Research Council of Norway project jetSTREAM under Grants NE/ L01047X/1 (IMPETUS) and 231716, respectively, for a contribution to the work presented here. EAB is supported in part by the NSF Climate and Large-Scale Dynamics Program under Grant 1545675 . Y-OK was supported by the NSF Climate and Large-Scale Dynamics Program under Grant 1355339. KW was supported by the Joint UK BEIS/Defra Met Office Hadley Centre Climate Programme (GA01101). RL was supported by the Met Office and the National Centre for Atmospheric Science. We acknowledge ECMWF and NOAA/ESRL for making the reanalysis data available (ERA-Interim, ERA20C, and 20CR). Support for the Twentieth Century Reanalysis Project dataset is provided by the U.S. Department of Energy Office of Science Innovative and Novel Computational Impact on Theory and Experiment (DOE INCITE) program, and the Office of Biological and Environmental Research (BER), and by the National Oceanic and Atmospheric Administration Climate Program Office. Monthly wavebreaking fields were downloaded from http://eraiclim. ethz.ch. We thank Christoph Raible, Gwendal Rivière, and Ed Gerber for their constructive feedback which helped to improve the paper.

\section{REFERENCES}

Archer, C. L., and K. Caldeira, 2008: Historical trends in the jet streams. Geophys. Res. Lett., 35, L08803, https://doi.org/ 10.1029/2008GL033614.

Athanasiadis, P. J., J. M. Wallace, and J. J. Wettstein, 2010: Patterns of wintertime jet stream variability and their relation to the storm tracks. J. Atmos. Sci., 67, 1361-1381, https://doi.org/ 10.1175/2009JAS3270.1.

Baker, H., T. Woollings, and C. Mbengue, 2017: Eddy-driven jet sensitivity to diabatic heating in an idealized GCM. J. Climate, 30, 6413-6431, https://doi.org/10.1175/JCLI-D-16-0864.1.

Barnes, E. A., 2013: Revisiting the evidence linking Arctic amplification to extreme weather in midlatitudes. Geophys. Res. Lett., 40, 4734-4739, https://doi.org/10.1002/grl.50880.

— and the variability of eddy-driven jets. J. Atmos. Sci., 68, 28932908, https://doi.org/10.1175/JAS-D-11-039.1.

$\longrightarrow$, and — 2012: Detection of Rossby wave breaking and its response to shifts of the midlatitude jet with climate change. J. Geophys. Res., 117, D09117, https://doi.org/10.1029/ 2012JD017469.

— their variability, to increased greenhouse gases in the CMIP5 models. J. Climate, 26, 7117-7135, https://doi.org/10.1175/ JCLI-D-12-00536.1. 
— , and D. W. Thompson, 2014: Comparing the roles of barotropic versus baroclinic feedbacks in the atmosphere's response to mechanical forcing. J. Atmos. Sci., 71, 177-194, https://doi.org/10.1175/JAS-D-13-070.1.

_, D. L. Hartmann, D. M. Frierson, and J. Kidston, 2010: Effect of latitude on the persistence of eddy-driven jets. Geophys. Res. Lett., 37, L11804, https://doi.org/10.1029/2010GL043199.

Benedict, J. J., S. Lee, and S. B. Feldstein, 2004: Synoptic view of the North Atlantic Oscillation. J. Atmos. Sci., 61, 121-144, https:// doi.org/10.1175/1520-0469(2004)061<0121:SVOTNA > 2.0.CO;2.

Brayshaw, D. J., B. Hoskins, and M. Blackburn, 2011: The basic ingredients of the North Atlantic storm track. Part II: Sea surface temperatures. J. Atmos. Sci., 68, 1784-1805, https:// doi.org/10.1175/2011JAS3674.1.

Buehler, T., C. C. Raible, and T. F. Stocker, 2011: The relationship of winter season North Atlantic blocking frequencies to extreme cold or dry spells in the ERA-40. Tellus, 63A , 174-187, https://doi.org/10.1111/j.1600-0870.2010.00492.x.

Cattiaux, J., Y. Peings, D. Saint-Martin, N. Trou-Kechout, and S. J. Vavrus, 2016: Sinuosity of midlatitude atmospheric flow in a warming world. Geophys. Res. Lett., 43, 8259-8268, https:// doi.org/10.1002/2016GL070309.

Compo, G. P., and Coauthors, 2011: The Twentieth Century Reanalysis Project. Quart. J. Roy. Meteor. Soc., 137, 1-28, https:// doi.org/10.1002/qj.776.

Cressman, G. P., 1950: Variations in the structure of the upper westerlies. J. Meteor., 7, 39-47, https://doi.org/10.1175/ 1520-0469(1950)007<0039:VITSOT >2.0.CO;2.

Croci-Maspoli, M., C. Schwierz, and H. Davies, 2007: Atmospheric blocking: Space-time links to the NAO and PNA. Climate Dyn., 29, 713-725, https://doi.org/10.1007/s00382-007-0259-4.

Czaja, A., 2009: Atmospheric control on the thermohaline circulation. J. Phys. Oceanogr., 39, 234-247, https://doi.org/10.1175/ 2008JPO3897.1.

Davini, P., C. Cagnazzo, S. Gualdi, and A. Navarra, 2012: Bidimensional diagnostics, variability, and trends of Northern Hemisphere blocking. J. Climate, 25, 6496-6509, https:// doi.org/10.1175/JCLI-D-12-00032.1.

_ J. von Hardenberg, and S. Corti, 2015: Tropical origin for the impacts of the Atlantic multidecadal variability on the EuroAtlantic climate. Environ. Res. Lett., 10, 094010, https:// doi.org/10.1088/1748-9326/10/9/094010.

Dee, D., and Coauthors, 2011: The ERA-Interim reanalysis: Configuration and performance of the data assimilation system. Quart. J. Roy. Meteor. Soc., 137, 553-597, https://doi.org/ 10.1002/qj.828.

Deser, C., J. W. Hurrell, and A. S. Phillips, 2017: The role of the North Atlantic Oscillation in European climate projections. Climate Dyn., 49, 3141-3157, https://doi.org/10.1007/ s00382-016-3502-z.

Edmon, H. J., B. J. Hoskins, and M. E. McIntyre, 1980: EliassenPalm cross sections for the troposphere. J. Atmos. Sci., 37, 2600-2616, https://doi.org/10.1175/1520-0469(1980)037<2600: EPCSFT>2.0.CO;2.

Eichelberger, S. J., and D. L. Hartmann, 2007: Zonal jet structure and the leading mode of variability. J. Climate, 20, 5149-5163, https://doi.org/10.1175/JCLI4279.1.

Feldstein, S. B., 2007: The dynamics of the North Atlantic Oscillation during the summer season. Quart. J. Roy. Meteor. Soc., 133, 1509-1518, https://doi.org/10.1002/qj.107.

Francis, J. A., and S. J. Vavrus, 2012: Evidence linking Arctic amplification to extreme weather in mid-latitudes. Geophys. Res. Lett., 39, L06801, https://doi.org/10.1029/2012GL051000.
Garfinkel, C. I., D. W. Waugh, and E. P. Gerber, 2013: The effect of tropospheric jet latitude on coupling between the stratospheric polar vortex and the troposphere. J. Climate, 26, 20772095, https://doi.org/10.1175/JCLI-D-12-00301.1.

Gastineau, G., and C. Frankignoul, 2012: Cold-season atmospheric response to the natural variability of the Atlantic meridional overturning circulation. Climate Dyn., 39, 37-57, https:// doi.org/10.1007/s00382-011-1109-y.

Gollan, G., R. J. Greatbatch, and T. Jung, 2015: Origin of variability in Northern Hemisphere winter blocking on interannual to decadal timescales. Geophys. Res. Lett., 42, $10037-$ 10 046, https://doi.org/10.1002/2015GL066572.

Gray, L. J., T. Woollings, M. Andrews, and J. Knight, 2016: Elevenyear solar cycle signal in the NAO and Atlantic/European blocking. Quart. J. Roy. Meteor. Soc., 142, 1890-1903, https:// doi.org/10.1002/qj.2782.

Häkkinen, S., P. B. Rhines, and D. L. Worthen, 2011: Atmospheric blocking and Atlantic multidecadal ocean variability. Science, 334, 655-659, https://doi.org/10.1126/science.1205683.

Hanna, E., T. E. Cropper, P. D. Jones, A. A. Scaife, and R. Allan, 2015: Recent seasonal asymmetric changes in the NAO (a marked summer decline and increased winter variability) and associated changes in the $\mathrm{AO}$ and Greenland blocking index. Int. J. Climatol., 35, 2540-2554, https://doi.org/10.1002/ joc.4157.

Hassanzadeh, P., Z. Kuang, and B. F. Farrell, 2014: Responses of midlatitude blocks and wave amplitude to changes in the meridional temperature gradient in an idealized dry GCM. Geophys. Res. Lett., 41, 5223-5232, https://doi.org/10.1002/ 2014 GL060764.

Held, I. M., 2005: The gap between simulation and understanding in climate modeling. Bull. Amer. Meteor. Soc., 86, 1609-1614, https://doi.org/10.1175/BAMS-86-11-1609.

_, and M. J. Suarez, 1994: A proposal for the intercomparison of the dynamical cores of atmospheric general circulation models. Bull. Amer. Meteor. Soc., 75, 1825-1830, https:// doi.org/10.1175/1520-0477(1994)075<1825:APFTIO>2.0.CO;2.

Hoskins, B. J., and D. J. Karoly, 1981: The steady linear response of a spherical atmosphere to thermal and orographic forcing. J. Atmos. Sci., 38, 1179-1196, https://doi.org/10.1175/ 1520-0469(1981)038<1179:TSLROA > 2.0.CO;2.

, and T. Ambrizzi, 1993: Rossby wave propagation on a realistic longitudinally varying flow. J. Atmos. Sci., 50, 1661-1671, https://doi.org/10.1175/1520-0469(1993)050<1661: RWPOAR $>2.0 . \mathrm{CO} ; 2$.

— , and T. Woollings, 2015: Persistent extratropical regimes and climate extremes. Curr. Climate Change Rep., 1, 115-124, https://doi.org/10.1007/s40641-015-0020-8.

Hurrell, J. W., and C. Deser, 2009: North Atlantic climate variability: The role of the North Atlantic Oscillation. J. Mar. Syst., 78, 28-41, https://doi.org/10.1016/j.jmarsys.2008.11.026.

Inatsu, M., and B. J. Hoskins, 2006: The seasonal and wintertime interannual variability of the split jet and the storm-track activity minimum near New Zealand. J. Meteor. Soc. Japan, 84, 433-445, https://doi.org/10.2151/jmsj.84.433.

Kunz, T., K. Fraedrich, and F. Lunkeit, 2009: Synoptic scale wave breaking and its potential to drive NAO-like circulation dipoles: A simplified GCM approach. Quart. J. Roy. Meteor. Soc., 135, 1-19, https://doi.org/10.1002/qj.351.

Li, C., and D. S. Battisti, 2008: Reduced Atlantic storminess during Last Glacial Maximum: Evidence from a coupled climate model. J. Climate, 21, 3561-3579, https://doi.org/10.1175/ 2007JCLI2166.1. 
_ and J. J. Wettstein, 2012: Thermally driven and eddy-driven jet variability in reanalysis. J. Climate, 25, 1587-1596, https:// doi.org/10.1175/JCLI-D-11-00145.1.

Martius, O., C. Schwierz, and H. C. Davies, 2007: Breaking waves at the tropopause in the wintertime Northern Hemisphere: Climatological analyses of the orientation and the theoretical LC1/2 classification. J. Atmos. Sci., 64, 2576-2592, https:// doi.org/10.1175/JAS3977.1.

McGraw, M. C., and E. A. Barnes, 2016: Seasonal sensitivity of the eddy-driven jet to tropospheric heating in an idealized AGCM. J. Climate, 29, 5223-5240, https://doi.org/10.1175/ JCLI-D-15-0723.1.

Merz, N., C. C. Raible, and T. Woollings, 2015: North Atlantic eddy-driven jet in interglacial and glacial winter climates. J. Climate, 28, 3977-3997, https://doi.org/10.1175/ JCLI-D-14-00525.1.

Nakamura, H., and T. Sampe, 2002: Trapping of synoptic-scale disturbances into the North-Pacific subtropical jet core in midwinter. Geophys. Res. Lett., 29, 1761, https://doi.org/ 10.1029/2002GL015535.

O'Reilly, C. H., M. Huber, T. Woollings, and L. Zanna, 2016: The signature of low frequency oceanic forcing in the Atlantic multidecadal oscillation. Geophys. Res. Lett., 43, 2810-2818, https://doi.org/10.1002/2016GL067925.

Papritz, L., and T. Spengler, 2015: Analysis of the slope of isentropic surfaces and its tendencies over the North Atlantic. Quart. J. Roy. Meteor. Soc., 141, 3226-3238, https://doi.org/ 10.1002/qj.2605.

Pelly, J. L., and B. J. Hoskins, 2003: A new perspective on blocking. J. Atmos. Sci., 60, 743-755, https://doi.org/10.1175/ 1520-0469(2003)060<0743:ANPOB > 2.0.CO;2.

Pinto, J. G., and C. C. Raible, 2012: Past and recent changes in the North Atlantic Oscillation. Wiley Interdiscip. Rev.: Climate Change, 3, 79-90, https://doi.org/10.1002/wcc.150.

, I. Gómara, G. Masato, H. F. Dacre, T. Woollings, and R. Caballero, 2014: Large-scale dynamics associated with clustering of extratropical cyclones affecting western Europe. J. Geophys. Res. Atmos., 119, 13 704-13 719, https://doi.org/ 10.1002/2014JD022305.

Poli, P., and Coauthors, 2016: ERA-20C: An atmospheric reanalysis of the twentieth century. J. Climate, 29, 4083-4097, https://doi.org/10.1175/JCLI-D-15-0556.1.

Raible, C. C., and Coauthors, 2006: Climate variability-observations, reconstructions, and model simulations for the AtlanticEuropean and Alpine region from 1500-2100 AD. Climatic Change, 79, 9-29, https://doi.org/10.1007/s10584-006-9061-2.

— , F. Lehner, J. F. G. Rouco, and L. F. Donado, 2014: Changing correlation structures of the Northern Hemisphere atmospheric circulation from 1000 to 2100 AD. Climate Past, 10, 537-550, https://doi.org/10.5194/cp-10-537-2014.

Rex, D. F., 1950: Blocking action in the middle troposphere and its effect upon regional climate. Tellus, 2, 275-301, https:// doi.org/10.3402/tellusa.v2i4.8603.

Rivière, G., and I. Orlanski, 2007: Characteristics of the Atlantic storm-track eddy activity and its relation with the North Atlantic Oscillation. J. Atmos. Sci., 64, 241-266, https://doi.org/ 10.1175/JAS3850.1.

, A. Laine, G. Lapeyre, D. Salas-Mélia, and M. Kageyama, 2010: Links between Rossby wave breaking and the North Atlantic Oscillation-Arctic Oscillation in present-day and Last Glacial Maximum climate simulations. J. Climate, 23, 2987-3008, https://doi.org/10.1175/2010JCLI3372.1.
Santos, J. A., T. Woollings, and J. G. Pinto, 2013: Are the winters 2010 and 2012 archetypes exhibiting extreme opposite behavior of the North Atlantic jet stream? Mon. Wea. Rev., 141, 3626-3640, https://doi.org/10.1175/ MWR-D-13-00024.1.

Scherrer, S. C., M. Croci-Maspoli, C. Schwierz, and C. Appenzeller, 2006: Two-dimensional indices of atmospheric blocking and their statistical relationship with winter climate patterns in the Euro-Atlantic region. Int. J. Climatol., 26, 233-249, https:// doi.org/10.1002/joc.1250.

Seager, R., Y. Kushnir, J. Nakamura, M. Ting, and N. Naik, 2010: Northern Hemisphere winter snow anomalies: ENSO, NAO and the winter of 2009/10. Geophys. Res. Lett., 37, L14703, https://doi.org/10.1029/2010GL043830.

Sellevold, R., S. Sobolowski, and C. Li, 2016: Investigating possible Arctic-midlatitude teleconnections in a linear framework. J. Climate, 29, 7329-7343, https://doi.org/10.1175/ JCLI-D-15-0902.1.

Spensberger, C., T. Spenger, and C. Li, 2017: Upper-tropospheric jet axis detection and application to the boreal winter 2013/14 Mon. Wea. Rev., 145, 2363-2374, https://doi.org/10.1175/ MWR-D-16-0467.1.

Sprenger, M., and Coauthors, 2017: Global climatologies of Eulerian and Lagrangian flow features based on ERA-Interim reanalyses. Bull. Amer. Meteor. Soc., 98, 1739-1748, https:// doi.org/10.1175/BAMS-D-15-00299.1.

Strong, C., and R. E. Davis, 2008: Variability in the position and strength of winter jet stream cores related to Northern Hemisphere teleconnections. J. Climate, 21, 584-592, https:// doi.org/10.1175/2007JCLI1723.1.

— breaking and the NAO/NAM. J. Atmos. Sci., 65, 2861-2876, https://doi.org/10.1175/2008JAS2632.1.

Sutton, R. T., and B. Dong, 2012: Atlantic Ocean influence on a shift in European climate in the 1990s. Nat. Geosci., 5, 788792, https://doi.org/10.1038/ngeo1595.

Vallis, G. K., E. P. Gerber, P. J. Kushner, and B. A. Cash, 2004: A mechanism and simple dynamical model of the North Atlantic Oscillation and annular modes. J. Atmos. Sci., 61, 264-280, https://doi.org/10.1175/1520-0469(2004)061<0264: AMASDM $>2.0 . \mathrm{CO} ; 2$

Wernli, H., and M. Sprenger, 2007: Identification and ERA-15 climatology of potential vorticity streamers and cutoffs near the extratropical tropopause. J. Atmos. Sci., 64, 1569-1586, https://doi.org/10.1175/JAS3912.1.

Williams, K., and Coauthors, 2015: The Met Office global coupled model 2.0 (GC2) configuration. Geosci. Model Dev., 8, 15091524, https://doi.org/10.5194/gmd-8-1509-2015.

Woollings, T., B. J. Hoskins, M. Blackburn, and P. Berrisford, 2008: A new Rossby wave-breaking interpretation of the North Atlantic Oscillation. J. Atmos. Sci., 65, 609-626, https:// doi.org/10.1175/2007JAS2347.1.

_ A. Hannachi, and B. Hoskins, 2010: Variability of the North Atlantic eddy-driven jet stream. Quart. J. Roy. Meteor. Soc., 136, 856-868, https://doi.org/10.1002/qj.625.

C. Czuchnicki, and C. Franzke, 2014: Twentieth century North Atlantic jet variability. Quart. J. Roy. Meteor. Soc., 140, 783-791, https://doi.org/10.1002/qj.2197.

, C. Franzke, D. Hodson, B. Dong, E. Barnes, C. Raible, and J. Pinto, 2015: Contrasting interannual and multidecadal NAO variability. Climate Dyn., 45, 539-556, https://doi.org/10.1007/ s00382-014-2237-y. 